\title{
Quantitative structure-activity relationships (QSARs) for the transformation of organic micropollutants during oxidative water treatment
}

\author{
Yunho Lee $^{a, b}$, Urs von Gunten ${ }^{a, c, d, *}$ \\ ${ }^{a}$ Eawag, Swiss Federal Institute of Aquatic Science and Technology, Ueberlandstrasse 133, CH-8600 Duebendorf, Switzerland \\ ${ }^{\mathrm{b}}$ Department of Environmental Science and Engineering, Gwangju Institute of Science and Technology (GIST), \\ Gwangju 500-712, Republic of Korea \\ ${ }^{\mathrm{c}}$ Institute of Biogeochemistry and Pollutant Dynamics, ETH Zurich, CH-8092 Zurich, Switzerland \\ ${ }^{\mathrm{d}}$ School of Architecture, Civil and Environmental Engineering (ENAC), Ecole Polytechnique Fédérale de Lausanne (EPFL), \\ CH-1015, Lausanne, Switzerland
}

\section{A R T I C L E I N F O}

\section{Article history:}

Received 12 January 2012

Received in revised form

30 May 2012

Accepted 5 June 2012

Available online 16 June 2012

\section{Keywords:}

QSAR

Micropollutant

Oxidation

Kinetics

Ozone

Chlorine dioxide

Chlorine

Ferrate $^{\text {vi }}$

\begin{abstract}
A B S T R A C T
Various oxidants such as chlorine, chlorine dioxide, ferrate ${ }^{\mathrm{VI}}$, ozone, and hydroxyl radicals can be applied for eliminating organic micropollutant by oxidative transformation during water treatment in systems such as drinking water, wastewater, and water reuse. Over the last decades, many second-order rate constants $(k)$ have been determined for the reaction of these oxidants with model compounds and micropollutants. Good correlations (quantitative structure-activity relationships or QSARs) are often found between the $k$-values for an oxidation reaction of closely related compounds (i.e. having a common organic functional group) and substituent descriptor variables such as Hammett or Taft sigma constants. In this study, we developed QSARs for the oxidation of organic and some inorganic compounds and organic micropollutants transformation during oxidative water treatment. A number of 18 QSARs were developed based on overall $412 \mathrm{k}$-values for the reaction of chlorine, chlorine dioxide, ferrate, and ozone with organic compounds containing electron-rich moieties such as phenols, anilines, olefins, and amines. On average, 303 out of 412 (74\%) $k$-values were predicted by these QSARs within a factor of 1/3-3 compared to the measured values. For $\mathrm{HO}^{\bullet}$ reactions, some principles and estimation methods of $k$-values (e.g. the Group Contribution Method) are discussed. The developed QSARs and the Group Contribution Method could be used to predict the $k$-values for various emerging organic micropollutants. As a demonstration, 39 out of 45 (87\%) predicted $k$-values were found within a factor 1/3-3 compared to the measured values for the selected emerging micropollutants. Finally, it is discussed how the uncertainty in the predicted $k$-values using the QSARs affects the accuracy of prediction for micropollutant elimination during oxidative water treatment.
\end{abstract}

(c) 2012 Elsevier Ltd. All rights reserved.

\footnotetext{
* Corresponding author. Tel.: +41 44 8235270; fax: +41 448235210.

E-mail addresses: yhlee42@gist.ac.kr (Y. Lee), vongunten@eawag.ch (U. von Gunten). 0043-1354/\$ - see front matter @ 2012 Elsevier Ltd. All rights reserved. http://dx.doi.org/10.1016/j.watres.2012.06.006
} 


\section{Contents}

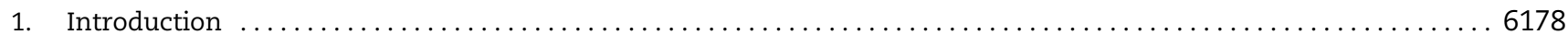

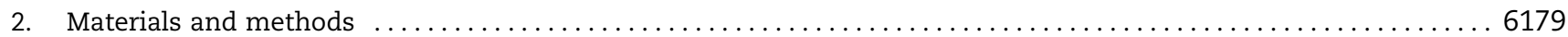

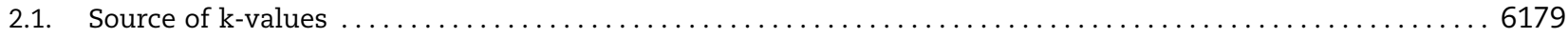

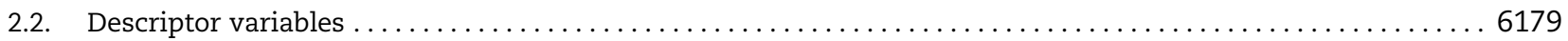

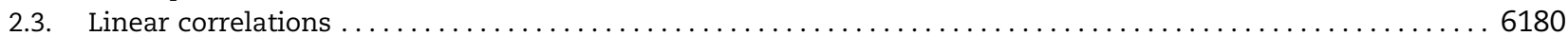

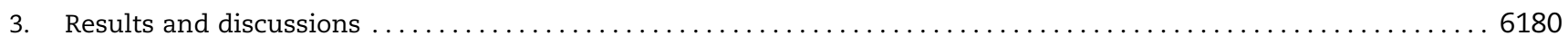

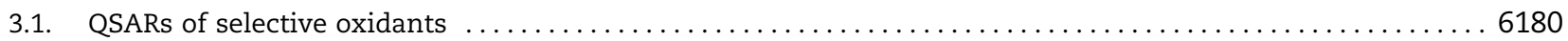

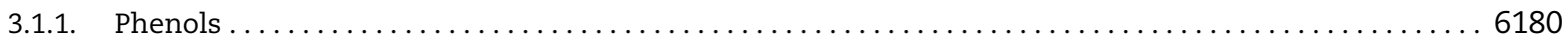

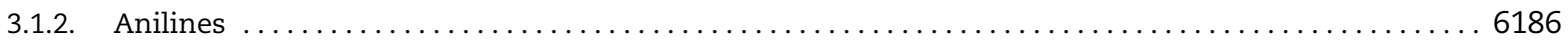

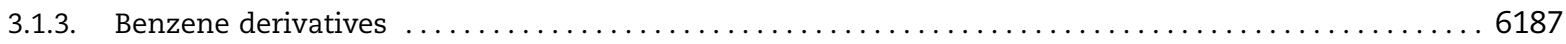

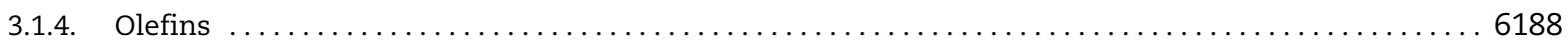

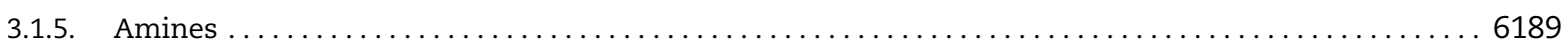

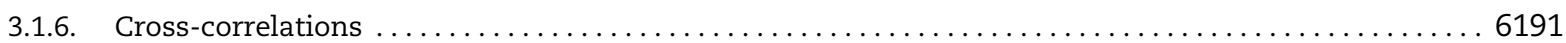

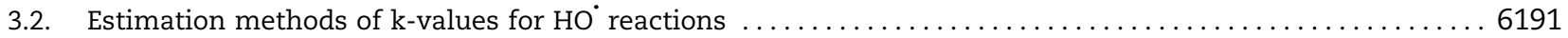

3.3. Prediction of $\mathrm{k}$-values for the reaction of selective oxidants and $\mathrm{HO}^{\circ}$ with micropollutants $\ldots \ldots \ldots \ldots \ldots 6192$

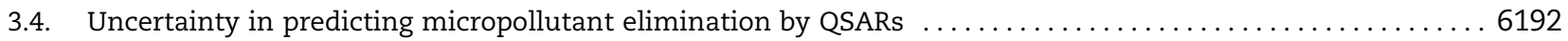

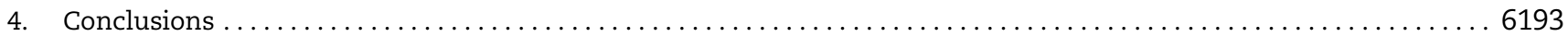

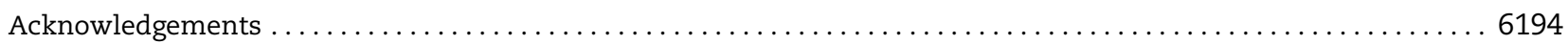

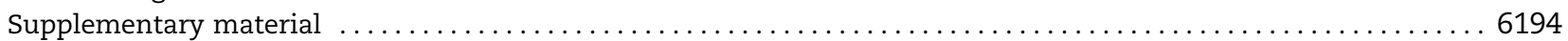

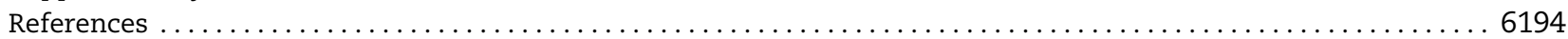

\section{Introduction}

Oxidation processes are widely applied to water treatment for the purpose of disinfection and oxidation. Target chemical pollutants for oxidation processes in drinking waters typically include inorganic (iron, manganese and arsenic, etc) and organic compounds (taste and odor compounds, fuel additives, pesticides, chlorinated solvents and algal toxins, etc). In recent years, oxidation processes have received increased attention as potential tools to eliminate so-called emerging micropollutants, such as hormones, pharmaceuticals and personal care products from wastewaters (Schwarzenbach et al., 2006, 2010; Ternes and Joss, 2006). These organic micropollutants are mainly derived from municipal wastewater effluents. Therefore, a polishing treatment of wastewater effluents by oxidation processes has been discussed and investigated from laboratory- to full-scale to minimize a discharge of micropollutants to the receiving waters (Snyder et al., 2006; Hollender et al., 2009; Gerrity et al., 2011; Zimmermann et al., 2011). Furthermore, wastewater reclamation facilities often employ multi-barrier treatment chains, which may include oxidation processes (Asano et al., 2007; Reungoat et al., 2010).

Ozone $\left(\mathrm{O}_{3}\right)$ and hydroxyl radicals $\left(\mathrm{HO}^{\circ}\right)$ with the latter being the main oxidant in 'advanced oxidation processes (AOPs)' have gained attention as a tool to transform micropollutants during treatment of not only drinking waters but also wastewaters (von Gunten, 2003; Snyder et al., 2006). Even though chlorine dioxide $\left(\mathrm{ClO}_{2}\right)$ and chlorine $(\mathrm{HOCl})$ have been used for disinfection as their primary purpose (Black \& Veatch Corporation, 2010), it has been realized that certain types of organic micropollutants can be significantly transformed by $\mathrm{ClO}_{2}$ and $\mathrm{HOCl}$ (Dodd and Huang, 2004, Pinkston and Sedlak, 2004; Huber et al., 2005; Deborde and von Gunten, 2008; Lee and von Gunten, 2009; Dodd et al., 2005). Additionally, ferrate ${ }^{\mathrm{VI}}\left(\mathrm{HFeO}_{4}^{-}\right)$has received attention as a dual function water treatment chemical, which can achieve oxidative transformation of micropollutants and removal of phosphate by iron-precipitation during wastewater treatment (Lee et al., 2009).

The transformation efficiency of micropollutants during oxidative water treatment depends on (1) the reactivity of the oxidant toward a target micropollutant and (2) toward the matrix components of water such as dissolved organic matter (Lee and von Gunten, 2010). The reactivity of an oxidant toward a compound has been quantified based on chemical kinetics, which employs rate laws and rate constants. Almost all reactions of water treatment oxidants (Ox) with dissolved compounds (P) typically follow second-order reaction kinetics. This yields the following rate equation:

$\mathrm{P}+\eta \mathrm{Ox} \rightarrow \mathrm{P}_{\text {oxid }}$

$-\mathrm{d}[\mathrm{P}] / \mathrm{dt}=k[\mathrm{P}][\mathrm{Ox}]=\eta k^{\prime}[\mathrm{P}][\mathrm{Ox}]$

where $k$ is a second-order rate constant for the consumption of $\mathrm{P}$ by $\mathrm{Ox}$, and $\eta$ is a stoichiometric factor for the amount of Ox that is depleted per $P$ that is transformed (i.e. $k=\eta k^{\prime}$ ). An integration of eq. (2) over a reaction time for a system which is closed for $\mathrm{P}$ (e.g. batch or plug-flow reactors) and under the condition of $[\mathrm{P}]<[\mathrm{Ox}]$ yields eq. (3). The condition of $[\mathrm{P}]<[\mathrm{Ox}]$ is almost always valid in oxidative water treatment because concentrations of $\mathrm{P}$ are in the $\mathrm{ngL}^{-1}$ to $\mu \mathrm{gL}^{-1}$ range while concentrations of $\mathrm{Ox}$ are in the $\mathrm{mg}^{-1}$ range. eq. (3) is useful when assessing and predicting micropollutant transformations during oxidative water treatment.

$[\mathrm{P}]_{\mathrm{t}} /[\mathrm{P}]_{0}=\exp \left(-k \int_{0}^{\mathrm{t}}[\mathrm{Ox}] \mathrm{dt}\right)$

The $k$-values represent the reactivity between $\mathrm{P}$ and $\mathrm{Ox}$ quantitatively and are one of the key parameters in the kinetic 
concept. Over the last decades, many $k$-values have been measured for the reaction of the aforementioned oxidants with a wide range of organic compounds in several different disciplines, such as water treatment chemistry, atmospheric chemistry, and biological chemistry (Buxton et al., 1988; Deborde and von Gunten, 2008; Hoigné and Bader, 1994; Lee et al., 2009; Neta et al., 1988; see also the kinetic data base Radiation Chemistry Data Center of the Notre Dame Radiation Laboratroy, available at http://kinetics.nist.gov/solution/). These $k$-values show that $\mathrm{O}_{3}, \mathrm{ClO}_{2}, \mathrm{HOCl}$ and $\mathrm{HFeO}_{4}^{-}$react fast with only electron-rich organic moieties (ERMs), such as activated aromatic compounds (i.e. phenol, aniline, and polycyclic aromatics), organosulfur compounds, and deprotonated amines. Additionally, $\mathrm{O}_{3}$ and $\mathrm{HFeO}_{4}^{-}$react with olefins (Lee and von Gunten, 2010). In contrast, $\mathrm{HO}^{\bullet}$ react very fast with almost any type of organic moieties even including aliphatic $\mathrm{C}-\mathrm{H}$ bonds (Buxton et al., 1988). Based on this difference in the reactivity, $\mathrm{O}_{3}, \mathrm{ClO}_{2}, \mathrm{HOCl}$ and $\mathrm{HFeO}_{4}^{-}$will be referred as 'selective oxidants' in the current paper as opposed to the less selective $\mathrm{HO}^{\circ}$.

Good correlations have been found between the $k$-values for an oxidation reaction of closely related compounds (e.g. possessing a common ERM) and substituent descriptor variables such as Hammett or Taft sigma constants (Canonica and Tratnyek, 2003). These QSARs (quantitative structure activity relationships) are useful in predicting $k$-values and thus transformation efficiency of micropollutants during oxidative water treatment. Especially, when considering the immense number and large structural diversity of synthetic organic compounds, which are often found in various water resources, the QSAR-based prediction method is very useful as a screening tool.

In this paper, we develop and summarize QSARs for the kinetics of the oxidation of organic compounds by the four water treatment oxidants, $\mathrm{O}_{3}, \mathrm{ClO}_{2}, \mathrm{HOCl}$ and $\mathrm{HFeO}_{4}^{-}$(these chemical formulae indicate the actual reactive species of these oxidants under typical conditions for water treatment and will be used to refer to these oxidants) that are relevant for organic micropollutants transformation during oxidative water treatment. Existing QSARs available for the selective oxidants in literature (Canonica and Tratnyek, 2003; Deborde and von Gunten, 2008; Gallard and von Gunten, 2002; Hoigné and Bader, 1983a; Lee et al., 2005; Pierpoint et al., 2001; Rebenne et al., 1996; Suarez et al., 2007) were updated by including the latest $k$-values available. In addition, several new QSARs were developed in this study. For $\mathrm{HO}^{\bullet}$ reactions, some principles and estimation methods of $k$-values are discussed. Furthermore, it was demonstrated how to use the developed QSARs to predict unknown $k$-values of selected organic micropollutants. Finally, the reliability and potential uncertainty involved in predicting $k$-values and micropollutant elimination by the QSARs are discussed.

\section{Materials and methods}

\subsection{Source of $\mathrm{k}$-values}

$k$-Values were obtained from various literature sources: $\mathrm{O}_{3}$ (Deborde et al., 2005; Dodd et al., 2006; Dowideit and von
Sonntag, 1998; Hoigné and Bader, 1983a,b; Neta et al., 1988; Pierpoint et al., 2001), $\mathrm{ClO}_{2}$ (Hoigné and Bader, 1994; Huber et al., 2005; Neta et al., 1988), HOCl (Deborde and von Gunten, 2008; Lee and von Gunten, 2009), and $\mathrm{HFeO}_{4}^{-}$(Lee et al., 2005, 2009). Some $k$-values of $\mathrm{O}_{3}$ and $\mathrm{ClO}_{2}$ are also available in an online data base, http://kinetics.nist.gov/ solution/. A complete list of the references is provided in the Supporting Information, SI-Excel-1

All $k$-values used in the QSAR analysis correspond to species-specific reactions. Among the oxidants, only chlorine and ferrate exist in two different species under near-neutral $\mathrm{pH}$ conditions: $\mathrm{HFeO}_{4}^{-}=\mathrm{FeO}_{4}^{-}+\mathrm{H}^{+}, \mathrm{pK}_{\mathrm{a}}=7.2$ (Sharma et al., 2001) and $\mathrm{HOCl}=\mathrm{OCl}^{-}+\mathrm{H}^{+}, \mathrm{pK}_{\mathrm{a}}=7.5$ (Albert and Serjeant, 1984). Since only the protonated species of chlorine and ferrate show appreciable reactivity, all $k$-values for chlorine and ferrate reactions correspond to the reactions of $\mathrm{HOCl}$ and $\mathrm{HFeO}_{4}^{-}$, respectively. Similarly among the ERMs, phenols and amines undergo acid-base speciation. In these cases, the $k$ values for the reaction with non-dissociated (i.e. protonated) and dissociated (i.e. deprotonated) species were treated separately.

\subsection{Descriptor variables}

In this study, Hammett $\sigma\left(\sigma, \sigma^{+}\right.$and $\left.\sigma^{-}\right)$and Taft $\sigma^{*}$ constants are mainly used in the QSAR analysis because they are the most common substituent descriptors in physical organic chemistry and relatively easily accessible and applicable (Hansch et al., 1991, 1995; Perrin et al., 1981). These constants are empirical parameters and obtained from thermodynamic or kinetic parameters for a specified reference reaction (e.g. ionization constants of benzoic acids) and a series of homologous reactants. These sigma constants express quantitatively the electron-donating (large negative value) or withdrawing (large positive value) properties of substituents. Hammett $\sigma$ constants are typically derived from and applied to aromatic compounds and thus include inductive and resonance effects of substituents. The $\sigma^{+}$and $\sigma^{-}$are specialized scales of $\sigma$ constants, which have been used to account for the stabilization of reaction centers by resonance interaction with substituents. Therefore, the $\sigma^{+}$scale differs from the $\sigma$ scale for the electron-donating substituents such as alkyl-, alkoxy-, and hydroxyl-groups. In contrast, the $\sigma^{-}$ scale differs from the $\sigma$ scale for the electron-withdrawing substituents such as nitro-, acetyl-, and cyano-groups. Taft $\sigma^{*}$ constants are derived from aliphatic compounds (e.g. ionization constants of esters) and typically represent inductive effects of substituents. Thus, Taft $\sigma^{*}$ constants are widely used to account for substituent effects especially in aliphatic systems.

To develop QSARs for aromatic compounds (i.e. phenols, anilines, and substituted benzenes), the three $\sigma$ constants (i.e. $\sigma, \sigma^{+}$, and $\sigma^{-}$) were tested to find the best correlations for the reaction of each selective oxidant. To account for the effects of multi-substituents on the aromatic ring, the $\sum \sigma_{o, m, p}$ (or $\sum \sigma_{o, m, p}^{+}$and $\left.\sum \sigma_{o, m, p}^{-}\right)$was used. The values were obtained by summing $\sigma_{o}, \sigma_{m}$, and $\sigma_{p}$ values for each relevant substituent, which are located in ortho-, meta-, and para-position, respectively. Most of these constants were obtained from literature (Hansch et al., 1991, 1995). The $\sigma_{o}^{+}$values were calculated from 
the relationship $\sigma_{o}^{+}=0.66 \sigma_{p}^{+}$, which accounts for the ortho effects (Jonsson et al., 1993). In addition, $\sigma_{0}^{-}$values were sometimes obtained from the relationship $\sigma_{o}^{-}=\sigma_{p}^{-}$when they are not available in literature (Hansch et al., 1991, 1995).

For aliphatic compounds such as amines and olefins, Taft $\sigma^{*}$ constants were used. The effects of substituents were accounted by using the $\sum \sigma^{*}$ which sums the $\sigma^{*}$ value of each substituent around the reaction center. Amines and amine derivatives have typically three substituents on the central nitrogen atom (i.e. $\left.\mathrm{R}_{1}-\mathrm{N}\left(\mathrm{R}_{2}\right)-\mathrm{R}_{3}\right)$, thus $\sum \sigma^{*}=\sigma^{*}\left(\mathrm{R}_{1}\right)+\sigma^{*}\left(\mathrm{R}_{2}\right)+$ $\sigma^{*}\left(\mathrm{R}_{3}\right)$. Likewise, olefins have four substituents on the double bond (i.e. $\left.\mathrm{R}_{1} \mathrm{R}_{2}-\mathrm{C}=\mathrm{C}-\mathrm{R}_{3} \mathrm{R}_{4}\right)$, accordingly, $\sum \sigma^{*}=\sigma^{*}\left(\mathrm{R}_{1}\right)+$ $\sigma^{*}\left(\mathrm{R}_{2}\right)+\sigma^{*}\left(\mathrm{R}_{3}\right)+\sigma^{*}\left(\mathrm{R}_{4}\right)$.

Descriptor variables for structurally complex substituents (especially the cases for many pharmaceuticals) were not directly available in literature. In these cases, a structural approximation has to be applied to estimate descriptor variables. The structural approximation is based on the principle that the inductive/resonance effects of atoms in substituents are attenuated with increasing distance of the atoms from a reaction center (Perrin et al., 1981). Therefore, only one or two neighboring atoms from a reaction center determine the inductive/resonance effects of whole substituents. For example, the cyclic-aliphatic ring attached to the phenolic moiety of $17 \alpha$-ethinylestradiol can be approximated to metaand para-dimethyl substituents (i.e. 3,4-dimethylphenol) because the rest of the aliphatic hydrocarbons in the rings do not have a significant influence to the electronic state of the phenolic moiety. Likewise, the structure of carbamazepine was approximated to 1,2-diphenylethene (see Supporting Information, SI-Excel-3 for more cases of structural approximations).

\subsection{Linear correlations}

Linear correlation equations were developed by plotting the logarithm of. $k$-values for reactions of oxidants with compounds versus the aforementioned substituent descriptor variables and then fitting according to the relationship, $\log (k)=\rho$ (descriptor variable) $+y_{0}$, where $\rho$ and $y_{0}$ represent the slope and intercept of the linear correlation, respectively. Cross-correlations were also tested between $k$-values for reaction with two oxidants. In these cases, the logarithm of $k$ values were fitted according to the relationship, $\log \left(k_{1}\right)=$ $a \times \log \left(k_{2}\right)+b$. For each correlation, all $k$-values for the reaction with model compounds or micropollutants were used for developing QSARs. Thus, no $k$-values were used to test the reliability of the developed QSARs. This was because for the several investigated correlations, the $k$-values for the reaction with micropollutants comprise of a significant portion (on average $24 \%$ ) of all available $k$-values. All statistical analyses were performed by a commercial software, Prism (Prism 5 for Windows, version 5.01, GraphPad Software, Inc., 2007). Further details of the QSAR analysis and results are provided in the Supporting Information, SI-EXCEL-1.

\section{Results and discussions}

The QSARs are presented for the reaction of the selective oxidants with four representative ERMs as reference compounds in the order of phenols, anilines, olefins, and amines. An additional QSAR is provided for the reaction of $\mathrm{O}_{3}$ with substituted benzenes, in which benzene is used as a reference compound. This is followed by the crosscorrelations among the $k$-values for $\mathrm{O}_{3}, \mathrm{ClO}_{2}$ and $\mathrm{HOCl}$. All the developed QSARs are shown in Table 1 and SI-Excel-1.

\subsection{QSARs of selective oxidants}

\subsubsection{Phenols}

The four selective oxidants $\left(\mathrm{O}_{3}, \mathrm{ClO}_{2}, \mathrm{HOCl}\right.$ and $\left.\mathrm{HFeO}_{4}^{-}\right)$show a significant reactivity toward phenols in aqueous solution. Phenols exist as non-dissociated $(\mathrm{PhOH})$ and dissociated species $\left(\mathrm{PhO}^{-}\right)$. Dissociated phenols have a higher electron density and thus are more reactive to electrophilic agents than non-dissociated ones. Therefore, different correlations are found for the non-dissociated and dissociated phenolic species. Figs. 1-4 show the developed correlations ( $k$ vs. $\sigma$ ) for each selective oxidant with dissociated phenols and nondissociated phenols.

$\mathrm{O}_{3}$ (Fig. 1). the linear correlations of $\mathrm{O}_{3}$ for $k_{\mathrm{PhOH}}$ and $k_{\mathrm{PhO}}$ are shown in Eqs. (4) and (5) in Table 1, respectively. The $\sigma_{o, m, p}^{+}$ scale was the best descriptor variable for both non-dissociated and dissociated phenols. A negative slope $\rho$ is typical for electrophilic reactions (i.e. oxidation reactions) and its magnitude reflects the sensitivity of the reaction to the substituent effect. Compared to the $\rho$ values of other oxidants (see below), $\mathrm{O}_{3}$ rate constants are less sensitive to the substituent variation. The $k_{\mathrm{PhO}^{-}}$-values are typically $>10^{7} \mathrm{M}^{-1} \mathrm{~s}^{-1}$, and even $>10^{9} \mathrm{M}^{-1} \mathrm{~s}^{-1}$ for some phenols with electron-donating substituents (e.g. $\left.\sum \sigma_{o, m, p}^{+}<0\right)$. The $k_{\mathrm{PhO}^{-}}-$values are about five orders of magnitude higher than the $k_{\mathrm{PhOH}}$-values. Therefore, in near-neutral and basic solutions (e.g. $\mathrm{pH}>7$ ), the apparent reaction rate constants at a given $\mathrm{pH}\left(k_{\mathrm{app}}\right)$ is mainly determined by the dissociated phenol species (i.e. $k_{\mathrm{app}}=\alpha k_{\mathrm{PhOH}}+(1-a) k_{\mathrm{PhO}^{-}}, \alpha$ : degree of dissociation, $\alpha=1 /\left(1+\mathrm{K} /\left[\mathrm{H}^{+}\right]\right), \mathrm{K}$ : dissociation constant). The reactivity $\mathrm{pK}$ for the ozone-phenol reaction is at about $4(\mathrm{pH}$ for which $\left.\alpha k_{\mathrm{PhOH}}=(1-\alpha) k_{\mathrm{PhO}^{-}}\right)$. This means that for a $\mathrm{pH}>4$, ozone reacts mainly with the phenolate species. In this respect, the uncertainty of predicted $k_{\text {app }}$-values is mainly affected by the uncertainty of eq. (5) rather than that of eq. (4) in Table 1.20 out of $24(83 \%) k_{\mathrm{PhOH}}$-values were predicted by eq. (4) within a factor of 1/3-3 compared to the measured ones. All $k_{\mathrm{PhO}^{-}}-$values were predicted by eq. (5) within a factor of $1 / 3-3$. The two dotted lines around the solid line in Fig. 1 represent the prediction error range of a factor of $1 / 3$ and 3 , respectively. A prediction error range of a factor of 9 was taken in this study as practical criterion for assessing goodness of correlations. This is based on the fact that many experimentally determined rate constants even for the same reaction typically show differences of up to a factor of 10 . It will be discussed later how significant the magnitude of the difference in $k$-value is for the uncertainty of the prediction of micropollutant elimination.

Currently, the rate constants $\left(k_{\mathrm{PhOH}}\right.$ and $\left.k_{\mathrm{PhO}^{-}}\right)$for the reaction of $\mathrm{O}_{3}$ are known for seven phenolic micropollutants, namely, $17 \alpha$-ethinylestradiol, 17 $\beta$-estradiol, estrone, estriol, bisphenol-A, 4-n-nonylphenol, and triclosan. Bisphenol-A has two $\mathrm{pK}_{\mathrm{a}}$ values and the corresponding rate constant of the 
Table 1 - Summary of the QSARs established for the selective oxidants $\left(\mathrm{O}_{3}, \mathrm{ClO}_{2}, \mathrm{HOCl}\right.$, and $\left.\mathrm{HFeO}_{4}^{-}\right)$.

\begin{tabular}{|c|c|c|c|c|c|c|}
\hline Eq. No. & Oxidant & Compound class & QSAR equation ${ }^{a}$ & $r^{2 b}$ & Sy. $x^{c}$ & $n^{\mathrm{d}}$ \\
\hline 4 & $\mathrm{O}_{3}$ & Non-dissociated phenols & $\log \left(k_{\mathrm{PhOH}}\right)=3.53( \pm 0.25)-3.24( \pm 0.69) \Sigma \sigma^{+}{ }_{\mathrm{o}, \mathrm{m}, \mathrm{p}}$ & 0.81 & 0.38 & 24 \\
\hline 5 & $\mathrm{O}_{3}$ & Dissociated phenols & $\log \left(k_{\text {pho- }}\right)=8.80( \pm 0.16)-2.27( \pm 0.30) \Sigma \sigma_{o, m, p}^{+}$ & 0.96 & 0.26 & 13 \\
\hline 6 & $\mathrm{ClO}_{2}$ & Non-dissociated phenols & $\log \left(k_{\mathrm{PhOH}}\right)=0.41( \pm 0.50)-4.69( \pm 1.13) \Sigma \sigma^{+}{ }_{\mathrm{o}, \mathrm{m}, \mathrm{p}}$ & 0.86 & 0.61 & 15 \\
\hline 7 & $\mathrm{ClO}_{2}$ & Dissociated phenols & $\log \left(k_{\text {PhO- }}\right)=8.03( \pm 0.13)-3.24( \pm 0.28) \Sigma \sigma_{o, m, p}^{-}$ & 0.95 & 0.34 & 32 \\
\hline 8 & $\mathrm{HOCl}$ & Dissociated phenols & $\log \left(k_{\text {PhO- }}\right)=4.46( \pm 0.15)-4.90( \pm 0.44) \Sigma \sigma_{o, m, p}^{-}$ & 0.94 & 0.45 & 35 \\
\hline 9 & $\mathrm{HFeO}_{4}^{-}$ & Non-dissociated phenols & $\log \left(k_{\mathrm{PhOH}}\right)=2.16( \pm 0.17)-2.59( \pm 0.52) \Sigma \sigma_{o, \mathrm{~m}, \mathrm{p}}^{+}$ & 0.93 & 0.23 & 11 \\
\hline 10 & $\mathrm{HFeO}_{4}^{-}$ & Dissociated phenols & $\log \left(k_{\text {PhO- }}\right)=4.36( \pm 0.13)-3.83( \pm 0.48) \Sigma \sigma_{o, m, p}^{+}$ & 0.96 & 0.33 & 14 \\
\hline 11 & $\mathrm{O}_{3}$ & Anilines & $\log \left(k_{\mathrm{ArNH} 2}\right)=7.15( \pm 0.25)-1.54( \pm 0.42) \Sigma \sigma_{o, \mathrm{~m}, \mathrm{p}}^{-}$ & 0.85 & 0.33 & 14 \\
\hline 12 & $\mathrm{ClO}_{2}$ & Anilines & $\log \left(k_{\mathrm{ArNH} 2}\right)=5.34( \pm 0.67)-2.47( \pm 0.94) \Sigma \sigma_{o, \mathrm{~m}, \mathrm{p}}^{+}$ & 0.99 & 0.30 & 4 \\
\hline 13 & $\mathrm{O}_{3}$ & Benzene derivatives & $\log \left(k_{\mathrm{BZD}}\right)=-0.04( \pm 0.38)-3.35( \pm 0.26) \Sigma \sigma_{\mathrm{p}}^{+}$ & 0.93 & 0.72 & 50 \\
\hline 14 & $\mathrm{O}_{3}$ & Olefins & $\log \left(k_{\text {olefin }}\right)=6.18( \pm 0.13)-0.49( \pm 0.03) \Sigma \sigma^{*}$ & 0.86 & 0.51 & 48 \\
\hline 15 & $\mathrm{O}_{3}$ & Amines and amine derivatives & $\log \left(k_{\text {amine }}\right)=6.13( \pm 0.21)-1.00( \pm 0.12) \Sigma \sigma^{*}$ & 0.86 & 0.61 & 54 \\
\hline 16 & $\mathrm{ClO}_{2}$ & Tertiary amines & $\log \left(k_{3^{\circ} \text { amine }}\right)=4.82( \pm 0.13)-1.72( \pm 0.40) \Sigma \sigma^{*}$ & 0.86 & 0.19 & 16 \\
\hline 17 & $\mathrm{ClO}_{2}$ & $\begin{array}{l}\text { Primary \& secondary } \\
\text { amines }\end{array}$ & $\log \left(k_{1^{\circ} \& 2^{\circ} \text { amine }}\right)=4.53( \pm 1.23)-4.51( \pm 1.64) \Sigma \sigma^{*}$ & 0.79 & 0.95 & 12 \\
\hline 18 & $\mathrm{HOCl}$ & Tertiary amines & $\log \left(k_{3^{\circ} \text { amine }}\right)=4.79( \pm 0.29)-1.96( \pm 0.80) \Sigma \sigma^{*}$ & 0.86 & 0.27 & 8 \\
\hline 19 & $\mathrm{HOCl}$ & $\begin{array}{l}\text { Primary amines \& } \\
\text { amine derivatives }\end{array}$ & $\log \left(k_{1^{\circ} \text { amine }}\right)=9.70( \pm 0.32)-2.10( \pm 0.18) \Sigma \sigma^{*}$ & 0.97 & 0.43 & 22 \\
\hline 20 & $\mathrm{O}_{3} / \mathrm{ClO}_{2}$ & Aromatics & $\log k_{\text {aromatic }}\left(\mathrm{O}_{3}\right)=3.19( \pm 0.57)+0.76( \pm 0.11) \log k_{\text {aromatic }}\left(\mathrm{ClO}_{2}\right)$ & 0.94 & 0.58 & 16 \\
\hline 21 & $\mathrm{O}_{3} / \mathrm{HOCl}$ & Aromatics & $\log k_{\text {aromatic }}\left(\mathrm{O}_{3}\right)=4.50( \pm 0.38)+0.96( \pm 0.11) \log k_{\text {aromatic }}(\mathrm{HOCl})$ & 0.94 & 0.66 & 24 \\
\hline
\end{tabular}

a In QSAR equations, values in parentheses are $95 \%$ confidence intervals.

$\mathrm{b} \mathrm{r}^{2}$ is the coefficient of correlation.

c Sy. $\mathrm{x}$ is the standard deviation of the linear regression and calculated as Sy. $\mathrm{x}=(\mathrm{SS} / \mathrm{df})^{1 / 2}$ where $\mathrm{SS}$ is the sum-of-squares of the distance of the linear regression from the data points and df is the degrees of freedom of the fit (i.e. $n-2)$.

$\mathrm{d} n$ is the number of data points.

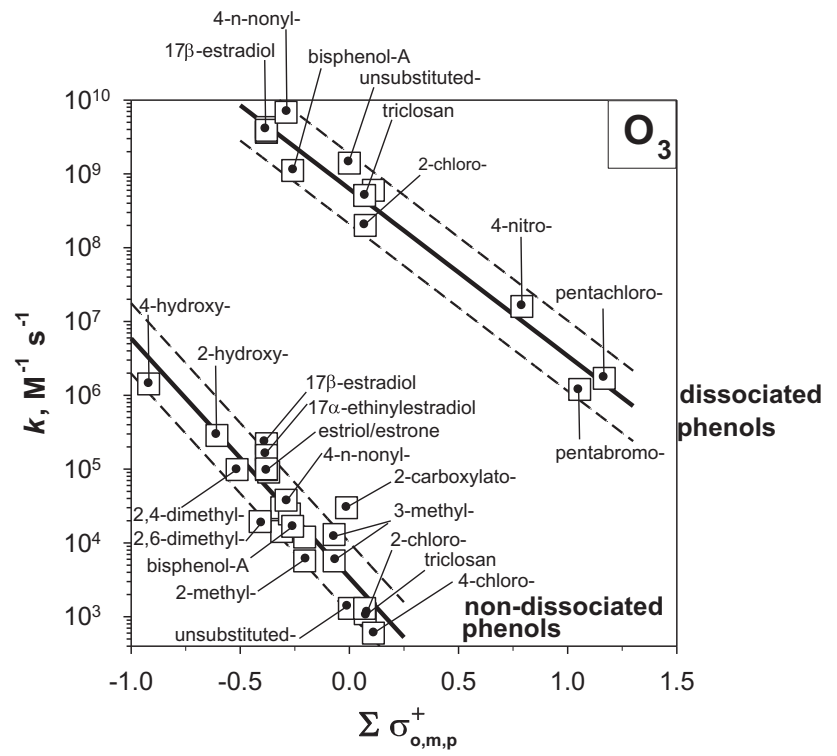

Fig. 1 - Correlations between the second-order rate constants $(k)$ for the reactions of ozone $\left(\mathrm{O}_{3}\right)$ with nondissociated phenols (eq. (4), Table 1) and dissociated phenols (eq. (5), Table 1) vs. $\sum \sigma_{o, m, p}^{+}$. Solid lines represent the obtained linear equations and dash lines represent the prediction error ranges of a factor of $1 / 3$ and 3 , respectively. Some symbols are not named due to space limitation: dissociated phenols such as 4-chlorophenolate, $17 \alpha-$ ethinylestradiol, estrone and estriol, non-dissociated phenols such as 4-methyl-, 2,3-dimethyl-, 3-hydroxy- and 3,4-dimethyl-phenol. The corresponding data can be found in SI-Excel-1.

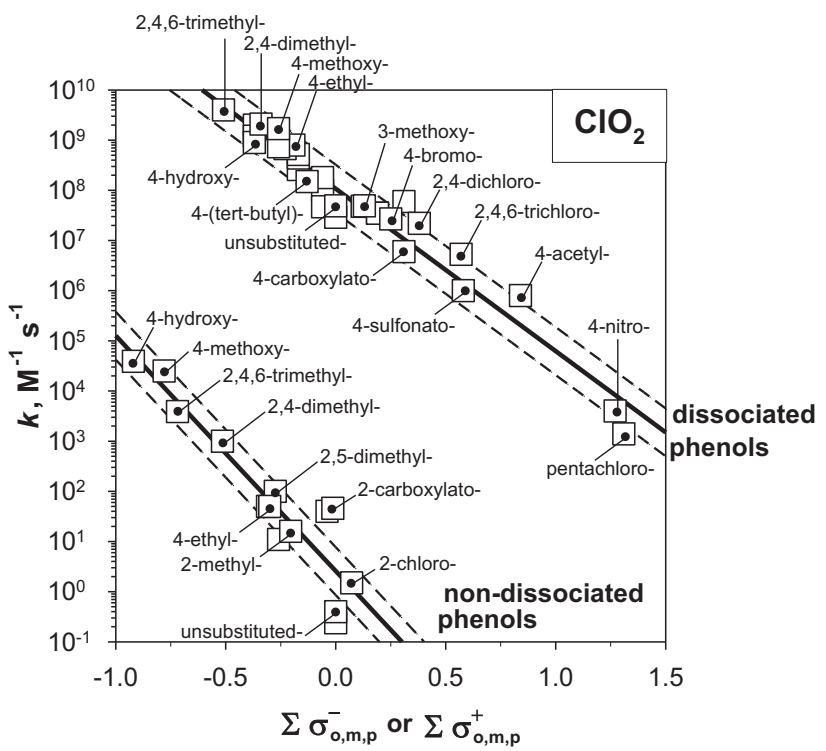

Fig. 2 - Correlations between the second-order rate constants ( $k$ ) for the reactions of chlorine dioxide $\left(\mathrm{ClO}_{2}\right)$ with non-dissociated phenols vs. $\sum \sigma_{o, m, p}^{+}$(eq. (6), Table 1), and with dissociated phenols vs. $\sum \sigma_{o, m, p}^{-}$(eq. (7), Table 1). Some symbols are not named due to space limitation: dissociated phenols such as 2-carboxylato-, 2-chloro-, 4-chloro-, 2-hydroxy-, 3-hydroxy-, 2-methoxy-, 2-methyl-, 3-methyl-, 4-methyl-, 2,5-dimethyl-phenolate, tyrosine and $17 \alpha$-ethinylestradiol: non-dissociated phenols such as 4-cyano-, 4-tert-butyl-, 3-hydroxy-, 2-methoxy-, 4-methyl-, 4-nitro-, 4-sulfonato-, tyrosine, 4-bromo-, and 4cyanophenol (data, SI-EXCEL-1). 


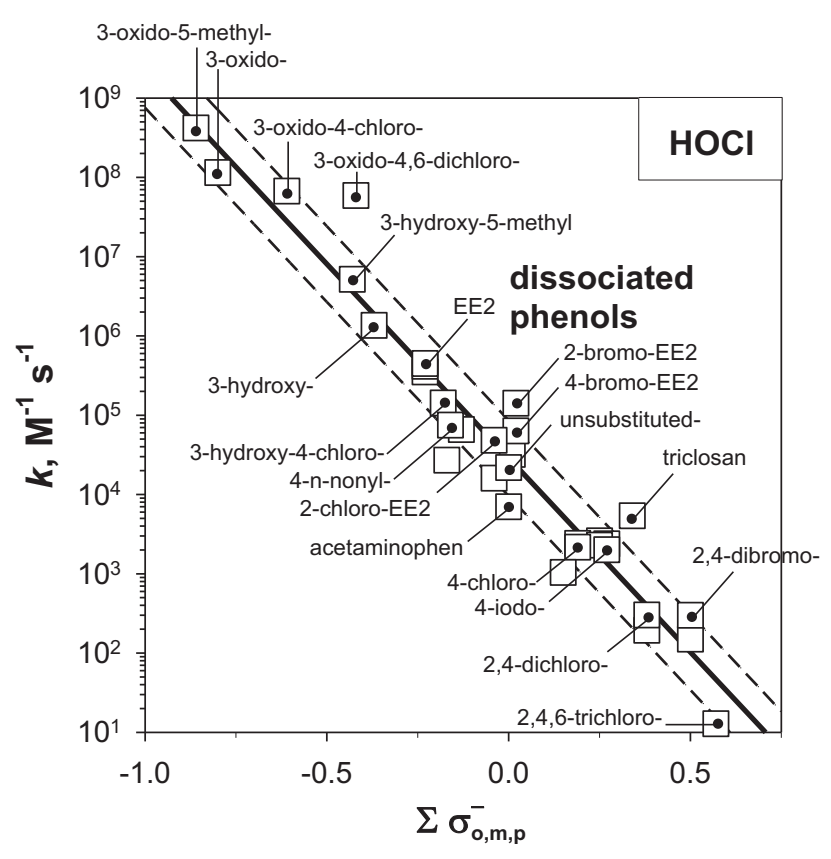

Fig. 3 - Correlation between the second-order rate constants $(k)$ for the reactions of chlorine ( $\mathrm{HOCl})$ with dissociated phenols vs. $\sum \sigma_{\text {o.m.p }}^{-}$(eq. (8), Table 1). EE2 represent $17 \alpha$-ethinylestradiol. Some symbols are not named due to space limitation: 2-chloro-, 2,6-dichloro-, 2bromo-, 4-bromo-, 2,6-dibromo-, 3-hydroxy-4,6-dichloroand 4-methyl-phenol, and bisphenol-A, 17 $\beta$-estradiol, estrone, estriol, 4-chloro-EE2, 2,4-dichloro-EE2 and 2,4dibromo-EE2 (data, SI-EXCEL-1).

single-dissociated $\left(k_{\mathrm{BPA}-}=1.06 \times 10^{9} \mathrm{M}^{-1} \mathrm{~s}^{-1}\right)$ and doublydissociated species $\left(k_{\mathrm{BPA2}-}=1.11 \times 10^{9} \mathrm{M}^{-1} \mathrm{~s}^{-1}\right)$ are reported (Deborde et al., 2005). The two nearly identical rate constant indicate that dissociation of one phenol has little influence to

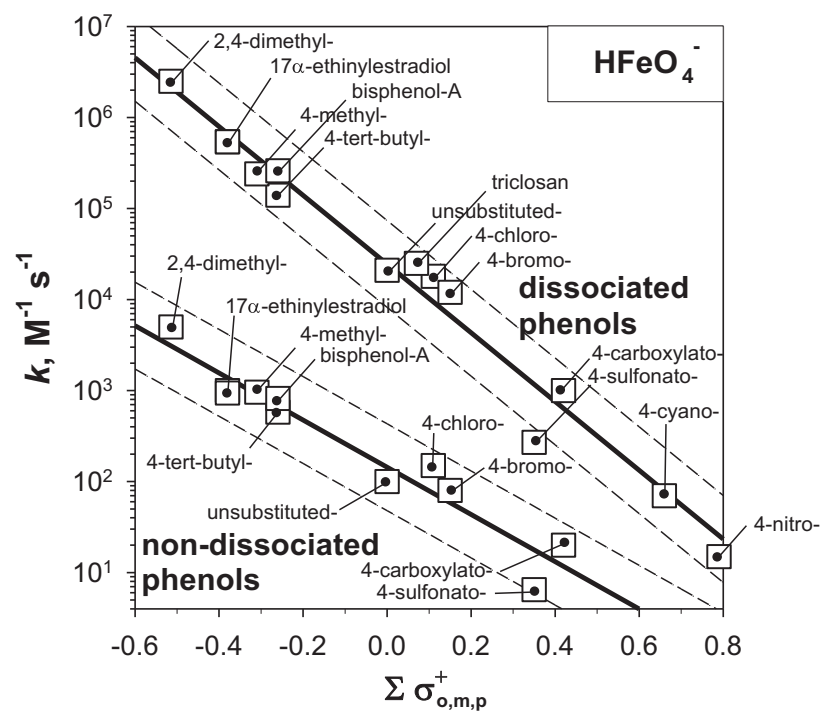

Fig. 4 - Correlation between the second-order rate constants $(k)$ for the reactions of ferrate ${ }^{\mathrm{VI}}\left(\mathrm{HFeO}_{4}^{-}\right)$with non-dissociated phenols (eq. (9), Table 1) and dissociated phenols vs. $\sum \sigma_{\text {o,m }, p}^{+}$(eq. (10), Table 1) (data, SI-EXCEL-1). the electronic state of the other phenol in bisphenol-A. In this study, the $k$-value of $1.1 \times 10^{9} \mathrm{M}^{-1} \mathrm{~s}^{-1}$ was therefore used for the two dissociated species of bisphenol-A. In all cases except the $k_{\mathrm{PhOH}}$-value for $17 \alpha$-ethinylestradiol and $17 \beta$-estradiol, the measured and predicted rate constants differ by less than a factor of 3 . However, the predicted $k_{\mathrm{PhO}^{-}}-$value for $17 \alpha-$ ethinylestradiol and $17 \beta$-estradiol were lower than the measured ones by a factor of 3.2 and 3.8, respectively. (see Table 2 and SI-Excel-1).

$\mathrm{ClO}_{2}$ (Fig. 2). The linear correlations of $\mathrm{ClO}_{2}$ for both $k_{\mathrm{PhOH}}$ and $k_{\mathrm{PhO}^{-}}$are shown in Eqs. (6) and (7) in Table 1, respectively. The $\sigma_{o, m, p}^{+}$scale was the best descriptor variables for nondissociated phenols, while the $\sigma_{o, m, p}^{-}$scale was the best for dissociated phenols (see SI- Excel-1). eq. (7) is quite similar to the QSAR equation developed by Tratnyek and Hoigne (i.e. $\log \left(k_{\mathrm{PhO}^{-}}\right)=8.2( \pm 0.2)-3.2( \pm 0.4) \sum \sigma_{o, m, p}^{-}, \quad n=23, \quad s=0.39$, $r=0.97$ ) (Tratnyek and Hoigne, 1994). Compared to $\mathrm{O}_{3}, \mathrm{ClO}_{2}$ shows at least one order of magnitude lower $k_{\mathrm{PhO}^{-}}-$-values. The $k_{\mathrm{PhO}^{-}}-$values are about eight orders of magnitude higher than the $k_{\mathrm{PhOH}}$-values. Therefore, the $k_{\mathrm{app}}$-values are controlled by the concentration of dissociated phenols (reactivity $\mathrm{pK}$ is about 2), which is similar to the case of $\mathrm{O}_{3} .10$ out of $15(67 \%)$ $k_{\mathrm{PhOH}}$-values were predicted by eq. (6) within a factor of $1 / 3-3$ compared. 25 out of $32(78 \%) k_{\mathrm{PhO}^{-}}-$values were predicted by eq. (7) within a factor of 1/3-3. Among various phenolic micropollutants, only the $k_{\mathrm{PhO}^{-}}$-value for $17 \alpha$-ethinylestradiol is known, which was well correlated with eq. (7) (a factor of 1.3 difference) (see Table 2 and SI-Excel-1).

$\mathrm{HOCl}$ (Fig. 3). For $\mathrm{HOCl}$, the best correlation is obtained for $\sigma_{o, m, p}^{-}$and shown in eq. (8) in Table 1. A very poor correlation was found for the reaction of $\mathrm{HOCl}$ with $\mathrm{PhOH}$ (e.g. $\mathrm{r}^{2}=0.36$ ). The poor correlation might be due to the poor reliability of the $k_{\mathrm{PhOH}}$-values. At acidic $\mathrm{pH}$, the reaction of $\mathrm{Cl}_{2}$ with $\mathrm{PhOH}$ (or acid-catalyzed reaction of $\mathrm{HOCl}$, i.e. $\mathrm{H}^{+}+\mathrm{HOCl}+\mathrm{PhOH}$ ) becomes important (Deborde and von Gunten, 2008) and therefore the $k_{\mathrm{PhOH}}$-values cannot be determined with accuracy because of the relative minor contribution of the reaction between $\mathrm{HOCl}$ and $\mathrm{PhOH}$ to the overall reaction.

Eq. (8) includes the $k_{\mathrm{PhO}^{-}}$-values with meta-hydroxyphenol, which could not be well correlated with those of other phenols by using the $\sigma_{o, m, p}^{+}$or $\sigma_{o, m, p}$ scale in previous studies (Deborde and von Gunten, 2008; Gallard and von Gunten, 2002; Rebenne et al., 1996). Therefore, the $\sigma_{o, m, p}^{-}$scale was investigated instead of $\sigma_{o, m, p}^{+}$or $\sigma_{o, m, p}$ scale in this case. The $\sigma_{m}^{-}$value for oxido substituent $\left(-\mathrm{O}^{-}\right)$was not available in literature, therefore it was estimated in this study by trial-and-error approach. The $\sigma_{m}^{-}$value for oxido substituent was initially guessed as ' -0.82 ' from the $\sigma_{p}^{-}$value for oxido substituent. The guessed value was used to calculate $\sum \sigma_{o, m, p}^{-}$values of 3-oxido-, 3-oxido-4-chloro- and 3-oxido-5-methyl-phenolates that were included in generating eq. (8). Next, a range of $\sigma_{m}^{-}$values (e.g. $-0.82 \pm 0.3)$ was tested to yield a best correlation coefficient $\left(\mathrm{r}^{2}\right)$ for eq. (8). A value of ' -0.8 ' resulted from this procedure. Based on the obtained $\sigma_{o, m, p}^{-}$scale, the $k_{\mathrm{PhO}^{-}}$-values for metahydroxyphenols could be well correlated with those of other phenols.

HOCl shows about four orders of magnitude lower $k_{\mathrm{PhO}^{-}}$-values than $\mathrm{O}_{3}$. In addition, the $k_{\mathrm{PhO}^{-}}$-values are more sensitive to the substituent variation than any other oxidants with a $\rho$ slope of -4.9 (even considering the difference in the $\sigma$ 
Table 2 - Prediction of second-order rate constants $(k)$ by using QSARs developed for the reaction of selective oxidants $\left(\mathrm{O}_{3}, \mathrm{ClO}_{2}\right.$, $\mathrm{HOCl}$, and $\left.\mathrm{HFeO}_{4}^{-}\right)$and $\mathrm{HO}^{\circ}(\mathrm{Group}$

Contribution Method, GCM) with selected micropollutants.

Micropollutant

$\sum \sigma_{o, m, p}^{+}{ }^{\mathrm{a}} \sum \sigma_{o, m, p}^{-}{ }^{\mathrm{a}} \sum \sigma^{* \mathrm{~b}} \quad$ Reaction

Measured $k$

Predicted $k \quad k_{\text {app }}$ at pH $7 \quad k_{\text {pred }} / k_{\text {meas }}{ }^{\mathrm{e}}$ Method $^{\mathrm{f}}$

Phenols

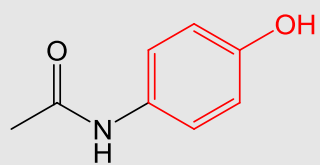

Acetaminophen $\mathrm{pK}_{\mathrm{a}}=9.7$ (analgesic)
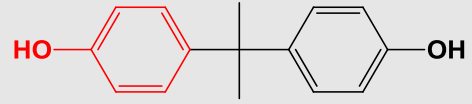

Bisphenol-A pK $K_{\mathrm{a}}=9.6$ and 10.2 (plasticizer)

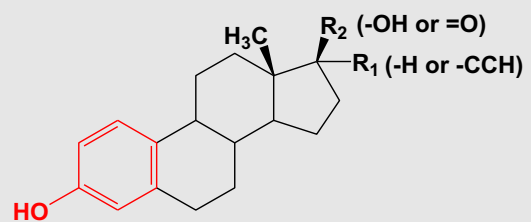

Steroid estrogens ${ }^{\mathrm{h}} \mathrm{pK}_{\mathrm{a}}=\sim 10.4$

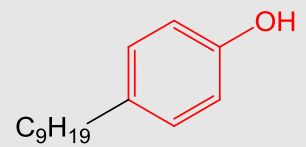

4-n-Nonylphenol $\mathrm{pK}_{\mathrm{a}}=10.7$ (nonionic surfactant degradation product)

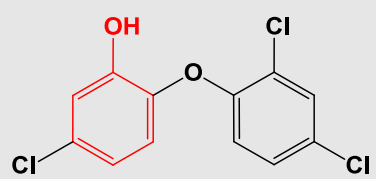

Triclosan $\mathrm{pK}_{\mathrm{a}}=8.1$ (antimicrobial disinfectant)
$-0.26$

$\mathrm{HO}^{\bullet}$
$\mathrm{O}_{3}+$ phenol
$\mathrm{O}_{3}+$ phenolate
$\mathrm{ClO}_{2}+$ phenol
$\mathrm{ClO}_{2}+$ phenolate
$\mathrm{HOCl}+$ phenolate
$\mathrm{HFeO}_{4}^{-}+$phenol
$\mathrm{HFeO}_{4}^{-}+$phenolate

$\mathrm{HO}$

$\mathrm{O}_{3}+$ phenol

$\mathrm{O}_{3}+$ phenolate

$\mathrm{ClO}_{2}+$ phenol

$\mathrm{ClO}_{2}+$ phenolate

$\mathrm{HOCl}+$ phenolate

$\mathrm{HFeO}_{4}^{-}+$phenol

$\mathrm{HFeO}_{4}^{-}+$phenolate

$\mathrm{HO}^{\circ}$

$\mathrm{O}_{3}+$ phenol

$\mathrm{O}_{3}$ + phenolate

$\mathrm{ClO}_{2}+$ phenol

$\mathrm{ClO}_{2}+$ phenolate

$\mathrm{HOCl}+$ phenolate

$\mathrm{HFeO}_{4}^{-}+$phenol

$\mathrm{HFeO}_{4}^{-}+$phenolate

$\mathrm{HO}^{\circ}$

$\mathrm{O}_{3}+$ phenol
$\mathrm{O}_{3}+$ phenolate

$\mathrm{O}_{3}+$ phenolate
$\mathrm{ClO}_{2}+$ phenol

$\mathrm{ClO}_{2}+$ phenolate

$\mathrm{HOCl}+$ phenolate

$\mathrm{HFeO}_{4}^{-}+$phenol

$\mathrm{HFeO}_{4}^{-}+$phenolate

$\mathrm{HO}^{\bullet}$

$\mathrm{O}_{3}+$ phenol

$\mathrm{O}_{3}$ + phenolate

$\mathrm{ClO}_{2}+$ phenol

$\mathrm{ClO}_{2}+$ phenolate

$\mathrm{HOCl}+$ phenolate

$\mathrm{HFeO}_{4}^{-}+$phenol

$\mathrm{HFeO}_{4}^{-}+$phenolate
$\left(\mathrm{M}^{-1} \mathrm{~s}^{-1}\right)^{\mathrm{c}}$

$\left(\mathrm{M}^{-1} \mathrm{~s}^{-1}\right)$

$\left(\mathrm{M}^{-1} \mathrm{~s}^{-1}\right)^{\mathrm{d}}$

$3.4 \times 10^{3}$

2.6

$1.1 \times 10^{8}$

$2.9 \times 10^{4}$

$1.4 \times 10^{2}$

$2.3 \times 10^{4}$

$10 \times 10^{9}$

$10 \times 10^{9}$

$2.4 \times 10^{4}$

$2.4 \times 10^{9}$

$4.3 \times 10^{1}$

$2.8 \times 10^{8}$

$1.2 \times 10^{5}$

$6.8 \times 10^{3}$

$2.3 \times 10^{5}$

$10 \times 10^{9}$

$5.8 \times 10^{4}$

$4.6 \times 10^{9}$

$1.6 \times 10^{2}$

$6.0 \times 10^{8}$

$3.9 \times 10^{5}$

$1.4 \times 10^{3}$

$6.5 \times 10^{5}$

$\begin{array}{lll}5.8 \times 10^{9} & - & \text { GCM } \\ 1.3 \times 10^{6} & - & \text { eq. (4) } \\ & - & \text { eq. (5) } \\ & - & \text { eq. (6) } \\ 2.1 \times 10^{5} & - & \text { eq. (7) } \\ 1.1 \times 10^{1} & 4.1 & \text { eq. (8) } \\ 1.2 \times 10^{2} & - & \text { eq. (9) } \\ & - & \text { eq. (10) } \\ 10 \times 10^{9} & 1.0 & \text { GCM } \\ 7.2 \times 10^{5} & - & \text { eq. (4) } \\ & 2.2 & \text { eq. (5) } \\ 1.8 \times 10^{5} & - & \text { eq. (6) } \\ & - & \text { eq. (7) } \\ 3.2 \times 10^{1} & 1.9 & \text { eq. (8) } \\ 6.2 \times 10^{2} & 0.8 & \text { eq. (9) } \\ & 0.9 & \text { eq. (10) } \\ 10 \times 10^{9} & \leq 1.4 & \text { GCMg } \\ 1.6 \times 10^{6} & \sim 0.3 & \text { eq. (4) } \\ & \sim 1.2 & \text { eq. (5) } \\ & - & \text { eq. (6) } \\ 1.8 \times 10^{5} & 1.3 & \text { eq. (7) } \\ 1.1 \times 10^{2} & 1.1 & \text { eq. (8) } \\ 7.3 \times 10^{2} & 1.5 & \text { eq. (9) } \\ & 1.2 & \text { eq. (10) } \\ 10 \times 10^{9} & - & \text { GCM } \\ 1.4 \times 10^{6} & 0.8 & \text { eq. (4) } \\ & 0.4 & \text { eq. (5) } \\ 7.1 \times 10^{4} & - & \text { eq. (6) } \\ 1.1 \times 10^{1} & - & \text { eq. (7) } \\ 5.5 \times 10^{2} & - & \text { eq. (8) } \\ & - & \text { eq. (9) } \\ 9.7 \times 10^{9} & - & \text { eq. (10) } \\ 3.8 \times 10^{7} & 1.5 & \text { eq. (4) } \\ & 0.9 & \text { eq. (5) } \\ 6.3 \times 10^{5} & - & \text { eq. (6) } \\ & - & \text { eq. (7) } \\ 1.2 \times 10^{2} & 0.1 & \text { eq. (8) } \\ & - & \text { eq. (9) } \\ & 0.5 & \text { eq. (10) }\end{array}$

(continued on next page) 
Anilines

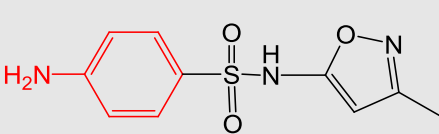

$\begin{array}{lll} & & \mathrm{O}_{3} \\ 0.57- & 0.94- & \mathrm{ClO}_{2}\end{array}$

Sulfamethoxazole (antibiotic)

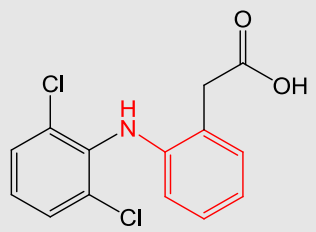

Diclofenac $\mathrm{pK}_{\mathrm{a}}=4.2$ (nonsteroidal anti-inflammatory)

Benzene derivatives

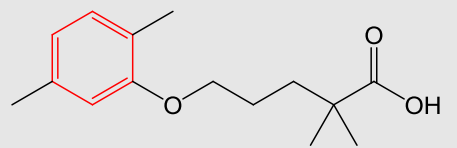

Gemfibrozil (antilipidemic)

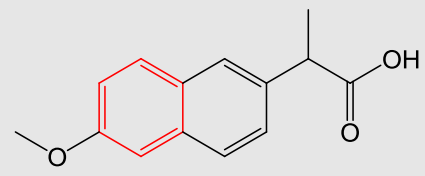

Naproxen (nonsteroidal anti-inflammatory)

Olefins

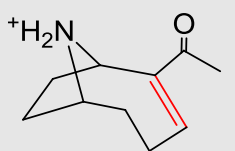

Anatoxin-protonated (cyanotoxin)

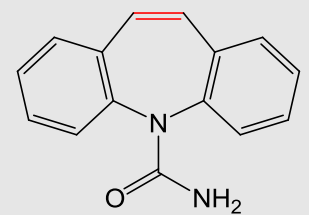

Carbamazepine (antiepileptic/analgesic)

$\mathrm{HFeO}_{4}^{-}$

$\begin{array}{lllll}5.5 \times 10^{9} & 8.1 \times 10^{9 *} & 5.5 \times 10^{9} & 1.5 & \text { GCM }^{\mathrm{g}} \\ 5.7 \times 10^{5} & 5.0 \times 10^{5} & 5.7 \times 10^{5} & 0.9 & \text { eq. (11) } \\ 7.9 \times 10^{3} & 8.5 \times 10^{3} & 7.9 \times 10^{3} & 1.1 & \text { eq. (12) }\end{array}$

$\begin{array}{lccrll}\mathrm{HO} & 7.5 \times 10^{9} & 10 \times 10^{9} & 7.5 \times 10^{9} & 1.3 & \text { GCM }^{g} \\ \mathrm{O}_{3} & 1 \times 10^{6} & 1.8 \times 10^{6} & 1 \times 10^{6} & 1.8 & \text { eq. (20) } \\ \mathrm{ClO}_{2} & 1.1 \times 10^{4} & 5.1 \times 10^{3} & 1.1 \times 10^{4} & 0.5 & \text { eq. (20) } \\ \mathrm{HOCl} & - & 3.7 \times 10^{1} & 2.8 \times 10^{1} & - & \text { eq. (21) }\end{array}$

$10 \times 10$

$\mathrm{O}_{3}$

$\mathrm{ClO}_{2}$

$\mathrm{HOCl}$

HO

$\mathrm{O}_{3}$

$\mathrm{ClO}_{2}$

$\mathrm{HOCl}$

$\mathrm{HO}^{\circ}$

$\mathrm{HFeO}_{4}^{-}$

3.60

$$
-
$$

0.7

$9.6 \times 10^{9}$ $2.0 \times 10^{5}$

$-$

2.4

$3 \times 10^{9}$

$2.8 \times 10$

$10 \times 10^{9}$

$2.4 \times 10^{4}$

$6-20$

$3 \times 10^{9}$
$2.8 \times 10^{4}$

$3.8-13$

$10 \times 10^{9}$
$4.6 \times 10^{4}$
$2.3 \times 10^{4}$
$5.9 \times 10^{1}$

0.5

$9.6 \times 10^{9}$

$2.0 \times 10^{5}$

$6.1 \times 10^{2}$

1.8

\begin{tabular}{|c|c|}
\hline 1.0 & $\mathrm{GCM}^{\mathrm{g}}$ \\
\hline - & eq. (13) \\
\hline & eq. (21) \\
\hline- & eq. (20) \\
\hline - & - \\
\hline 1.0 & $\mathrm{GCM}^{\mathrm{g}}$ \\
\hline 0.4 & eq. (21) \\
\hline & eq. (20) \\
\hline & eq. (21) \\
\hline
\end{tabular}

6.8
$8.8 \times 10^{9}$
$3 \times 10^{5}$

$1.1 \times 10^{2}$ 


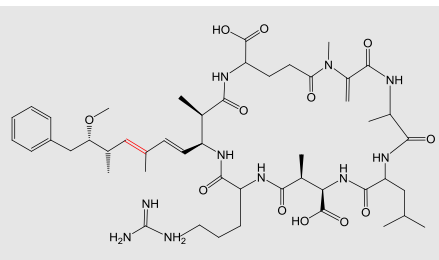

\section{Microcystin-LR (cyanotoxin)}

Amines

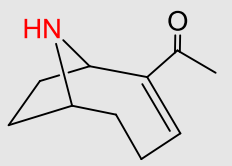

Anatoxin-a-deprotonated $\mathrm{pK}_{\mathrm{a}}=9.36$ (cyanotoxin)

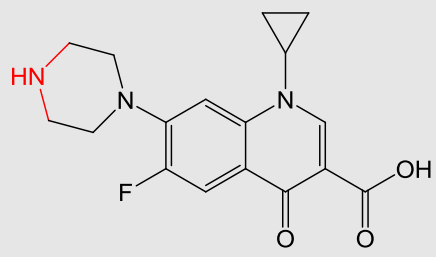

Ciprofloxacin $\mathrm{pK}_{\mathrm{a}}=8.8$ (antibiotic)

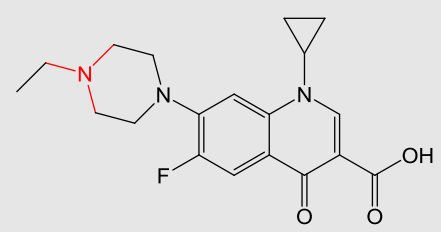

Enrofloxacin $\mathrm{pK}_{\mathrm{a}}=7.7$ (antibiotic)

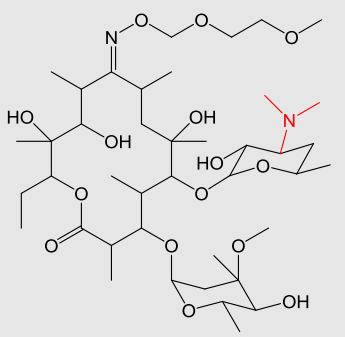

Hо

$\mathrm{O}_{3}$
$\mathrm{ClO}_{2}$

$\mathrm{ClO}_{2}$
$\mathrm{HOCl}$

$10 \times 10^{9}$

$1.3 \times 10^{6}$

$3.5 \times 10^{4}$

$4.5 \times 10^{9}$

$1.3 \times 10^{5}$

$5.9 \times 10^{3}$

$\mathrm{GCM}^{\mathrm{g}}$

$-$

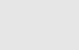

$5.4 \times 10^{9}$
$4.5 \times 10^{6}$
$1.4 \times 10^{4}$

$1.4 \times 10^{4}$

$10 \times \times 10^{9}$

$9.4 \times 10^{5}$

$3.6 \times 10^{4}$

$3.1 \times 10^{4}$

$5.4 \times 10^{9}$

$2.8 \times 10^{4}$ $8.8 \times 10^{1}$ $1.5 \times 10^{2}$

GCM

eq. (15)

eq. (16) eq. (18) 


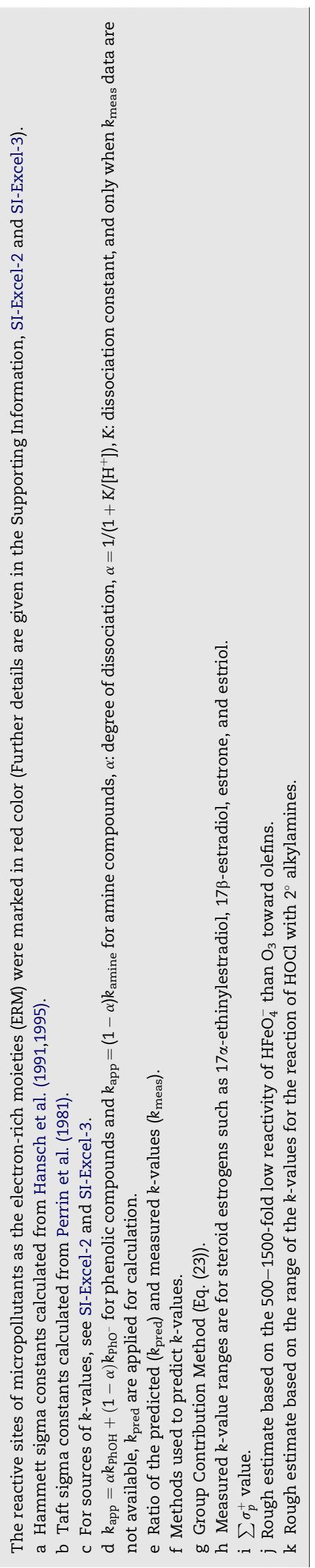

scale). The $k_{\mathrm{PhO}^{-}}-$values are about four orders of magnitude higher than the $k_{\mathrm{PhOH}}$-values, therefore the $k_{\mathrm{app}}$-values are also controlled by the concentration of dissociated phenols, which is similar to the case of $\mathrm{O}_{3}$ and $\mathrm{ClO}_{2}$. 28 out of $35(80 \%)$ $k_{\mathrm{PhO}^{-}}-$-values were predicted by eq. (8) within a factor of $1 / 3-3$. Currently, the $k_{\mathrm{PhO}^{-}}-$values for the reaction of $\mathrm{HOCl}$ are known for fourteen phenolic micropollutants. These include acetaminophen, bisphenol-A, 2-bromo-17 $\alpha$-ethinylestradiol (2bromo EE2), 4-bromo EE2, 2-chloro EE2, 4-chloro EE2, 2,4dibromo-EE2, 2,4-dichloro-EE2, EE2, 17 $\beta$-estradiol (E2), estriol (E3), estrone (E1), 4-nonylphenol, and triclosan. In most cases, eq. 8 yields good predictions for the $k_{\mathrm{PhO}^{-}}$-values of these micropollutants with differences of less than a factor of 3 . However, the predicted $k_{\mathrm{PhO}^{-}}$-value for acetaminophen was lower than the measured one by a factor of 4.1. In addition, the predicted $k_{\mathrm{PhO}^{-}}$-value for triclosan was higher than the measured one by a factor of 8.6 (see Table 2 and SI-Excel-1).

$\mathrm{HFeO}_{4}^{-}$(Fig. 4). For $\mathrm{HFeO}_{4}^{-}$, the best correlations are obtained when using $\sigma_{o, m, p}^{+}$scales and are shown in Eqs. 9 and 10 in Table 1 , respectively. The $k_{\mathrm{PhO}^{-}}$-values of $\mathrm{HFeO}_{4}^{-}$were similar to $\mathrm{HOCl}$ but several orders of magnitude lower than those of $\mathrm{O}_{3}$ and $\mathrm{ClO}_{2}$. Interestingly, the $k_{\mathrm{PhOH}^{-}}$-values of $\mathrm{HFeO}_{4}^{-}$were considerably higher than those of $\mathrm{ClO}_{2}$ and $\mathrm{HOCl}$. In addition, the $k_{\mathrm{PhOH}}$-values were just about two orders of magnitude lower than the $k_{\mathrm{PhO}^{-}}$-values, which is a relatively small difference compared to those of other oxidants (e.g. more than four orders of magnitude difference for $\mathrm{O}_{3}, \mathrm{ClO}_{2}$ and $\mathrm{HOCl}$ ). From the comparison of the $\rho$ slopes, $\mathrm{HFeO}_{4}^{-}$was found less selective to non-dissociated phenols $(\rho=-2.59)$ than dissociated ones $(\rho=-3.78)$, which is in contrast to the cases of $\mathrm{O}_{3}$ and $\mathrm{ClO}_{2}$. These observations seem to suggest that the mechanism for the reaction of $\mathrm{HFeO}_{4}^{-}$with non-dissociated phenols is different from that with dissociated phenols.

Due to the small difference in the $k_{\mathrm{PhOH}^{-}}$and $k_{\mathrm{PhO}^{-}}$-values, both non-dissociated and dissociated phenol species are important in controlling the $k_{\mathrm{app}}$-values. The reactivity $\mathrm{pK}$ for $17 \alpha$-ethinylestradiol is at 7.5. Therefore, the $k_{\text {app }}$-values are controlled by the fraction of non-dissociated phenols at $\mathrm{pH}$ $<7.5$ while it is dominated by the fraction of dissociated phenols at $\mathrm{pH}>7.5$ (see above).

All $11 k_{\mathrm{PhOH}^{-}}$-values were predicted by eq. (9) with a difference of less than a factor of 3.13 out of 14 (93\%) $k_{\mathrm{PhO}^{-}}$-values were predicted by eq. (10) within less than a factor of 3 . Currently, the rate constants $\left(k_{\mathrm{PhOH}}\right.$ and $\left.k_{\mathrm{PhO}^{-}}\right)$for the reaction of $\mathrm{HFeO}_{4}^{-}$are known for four phenolic micropollutants, namely, bisphenol-A, $17 \alpha$-ethinylestradiol, $17 \beta$-estradiol and triclosan. For these four micropollutants, the predicted $k$ values lie within a factor of 2 relative to the measurements (see Table 2 and SI-Excel-1).

\subsubsection{Anilines}

All selective oxidants show a high reactivity to anilines $\left(k>10^{2} \mathrm{M}^{-1} \mathrm{~s}^{-1}\right)$. Compared to phenols, however, the number of available $k$-values is significantly lower for $\mathrm{ClO}_{2}, \mathrm{HOCl}$, and $\mathrm{HFeO}_{4}^{-}$. The three sets of Hammett $\sigma$ constants were tested for the correlation analysis.

$\mathrm{O}_{3}$ (Fig. 5). The linear correlation of $\mathrm{O}_{3}$ for $k_{\mathrm{ArNH} 2}$ is shown in eq. (11) in Table 1. For ozone, the $\sigma_{o, m, p}^{-}$scale yielded the best correlation. Even though the $k_{\mathrm{ArNH} 2}$-values are one or two orders of magnitude lower than $k_{\mathrm{PhO}^{-}}$-values (eq. (5) vs. eq. 


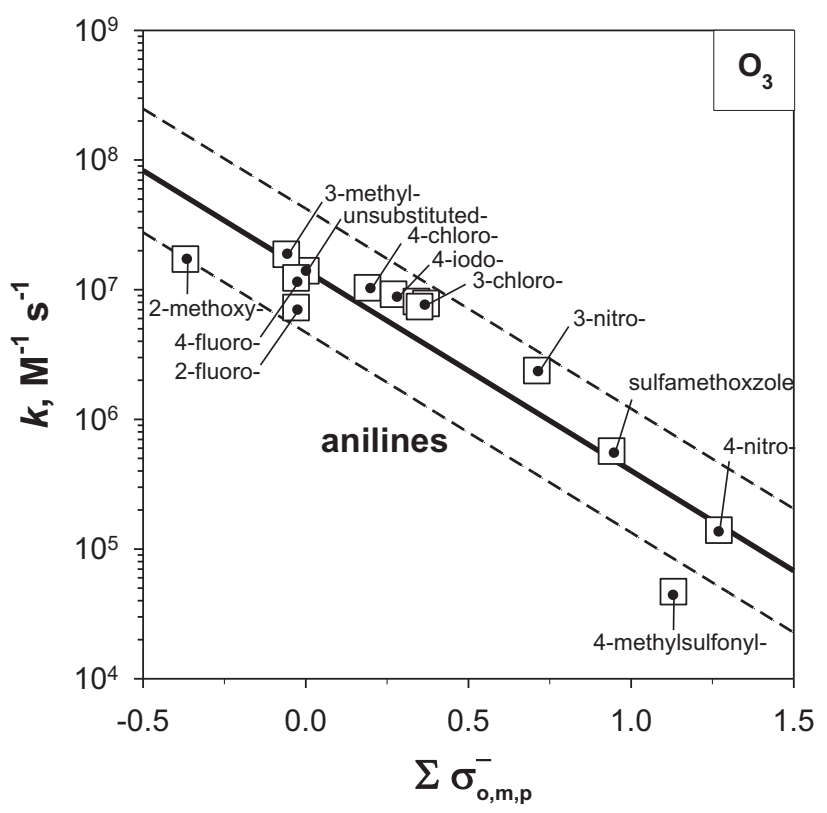

Fig. 5 - Correlation between the second-order rate constants $(k)$ for the reactions of $\mathrm{O}_{3}$ with anilines vs. $\sum \sigma_{\text {o,m,p }}^{-}$(Eq. (11), Table 1) (data, SI-EXCEL-1).

(11)), the $k_{\mathrm{app}}$-values for the reaction of $\mathrm{O}_{3}$ at near-neutral $\mathrm{pH}$ are higher with anilines than phenols because anilines do not change their speciation ( $\mathrm{pK}_{\mathrm{a}}$ values of anilines $<5$ ). The $\rho$ slope is -1.54 , thus the reactions are relatively less sensitive to the substituent effects. 12 out of $14(86 \%) k_{\mathrm{ArNH}}$-values were predicted by Eq. (11) within a factor 1/3-3. Currently, the $k_{\text {ArNH2}}$-value of $\mathrm{O}_{3}$ is known only for sulfamethoxazole as aniline-containing micropollutants. Eq. (11) predicts well the $k_{\mathrm{ArNH} 2}$-value of sulfamethoxazole within a factor of 1.2 (see Table 2 and SI-Excel-1).

$\mathrm{ClO}_{2}$ (Fig. 6). The linear correlation of $\mathrm{ClO}_{2}$ for $k_{\mathrm{ArNH} 2}$ is shown in Eq. (12) in Table 1. Compared to $\mathrm{O}_{3}, \mathrm{ClO}_{2}$ shows about two orders of magnitude lower $k$-values for non-substituted aniline. Because of the small number of $k$-values available $(\mathrm{n}=4)$, the obtained correlation for $\mathrm{ClO}_{2}$ is less reliable than other correlations presented in this study. Nevertheless, the $k_{\mathrm{ArNH} 2}$-value for the reaction of chlorine dioxide with sulfamethoxazole is well correlated with Eq. (12) within a factor of 1.1 (see Table 2 and SI-Excel-1).

$\mathrm{HOCl}$ and $\mathrm{HFeO}_{4}^{-}$. Even though $\mathrm{HOCl}$ and $\mathrm{HFeO}_{4}^{-}$show a considerable reactivity to aniline (i.e. $k>10^{2} \mathrm{M}^{-1} \mathrm{~s}^{-1}$ ), only a few rate constants are available for substituted anilines. One $k_{\mathrm{ArNH} 2}$-value is available for $\mathrm{HOCl}$, which is the reaction with sulfamethoxazole $\left(k=2.4 \times 10^{3} \mathrm{M}^{-1} \mathrm{~s}^{-1}\right.$, Dodd and Huang, 2004). For $\mathrm{HFeO}_{4}^{-}, k_{\mathrm{ArNH} 2}$-values have been determined for the reaction with aniline and sulfonamide-antimicrobial compounds (sulfadimethoxine, sulfamethizole, sulfamethazine, sulfamethoxazole and sulfisoxazole) (Lee et al., 2009; Sharma et al., 2006). However, it was proposed that the determined $k_{\mathrm{ArNH} 2}$-values for the reaction of $\mathrm{HFeO}_{4}^{-}$might represent the $k$-value for the reaction of aniline-ferrate intermediates with aniline (Lee et al., 2009). More kinetic studies are needed to be able to develop reliable QSARs for the reactions of anilines, especially with $\mathrm{HOCl}$, and $\mathrm{HFeO}_{4}^{-}$.

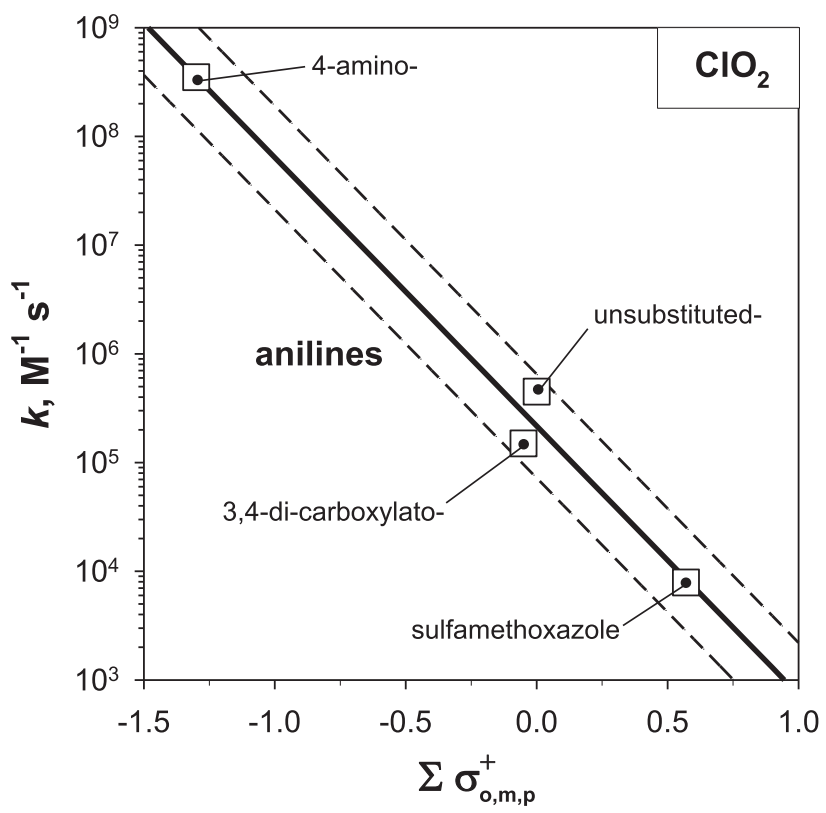

Fig. 6 - Correlation between the second-order rate constants ( $k$ ) for the reactions of $\mathrm{ClO}_{2}$ with anilines vs. $\sum \sigma_{o, m, p}^{+}$(Eq. (12), Table 1) (data, SI-EXCEL-1).

\subsubsection{Benzene derivatives}

$\mathrm{O}_{3}$ shows considerable reactivity, albeit with a wide range of reactivity towards several sub-classes of benzene derivatives (BZD) such as phenols, anilines, alkyl-/alkoxy-benzenes, and halo-benzenes etc $\left(0.1<k<10^{10} \mathrm{M}^{-1} \mathrm{~s}^{-1}\right)$. Currently, there are at least $67 \mathrm{k}$-values available for the reaction of $\mathrm{O}_{3}$ with benzene derivatives, which may produce useful QSARs. Correlation analysis was performed based on benzene as a reference compound and using different types of the Hammett $\sigma$ constants. In the case of mono- or di-substituted benzenes, multiple sites for $\mathrm{O}_{3}$ attack are possible. Each scenario of $\mathrm{O}_{3}$ attack results in a different value of $\sum(\sigma)$. To solve this problem, $\mathrm{O}_{3}$ attack was assumed to occur at the site where the $\sum(\sigma)$ value is the lowest. This assumption is reasonable because more negative $\sigma$ values indicate more electron density on the benzene, which would be more susceptible to electrophilic attack. Overall, a good correlation was found only when applying a few restrictions as follows: 1 ) $\sum \sigma_{p}^{+}$had to be used as sole descriptor variable. This means that $\sigma_{p}^{+}$was used instead of $\sigma_{o}^{+}$and $\sigma_{m}^{+}$, and 2) the $k$-values for the reaction of $\mathrm{O}_{3}$ with fourteen anilines and three other compounds such as 2,4-dichlorophenolate, nitrobenzene, and benzaldehyde were excluded as outliers in the QSAR. Fig. 7 shows the resulting linear correlation for the reaction of $\mathrm{O}_{3}$ with benzene derivatives (BZD). The obtained Eq. (13) is shown Table 1 (see also SI-EXCEL-1).

The two restrictions applied for developing Eq. (13) can be acceptable when considering the diverse structures of the compounds and the corresponding different reaction mechanisms for their reaction with $\mathrm{O}_{3}$. Here, our intention was to develop a useful semi-empirical correlation covering as many benzene derivatives as possible with minimal restrictions. Eq. (13) predicts 30 out of $50(60 \%) k_{\mathrm{BZD}}$-values within a factor of 


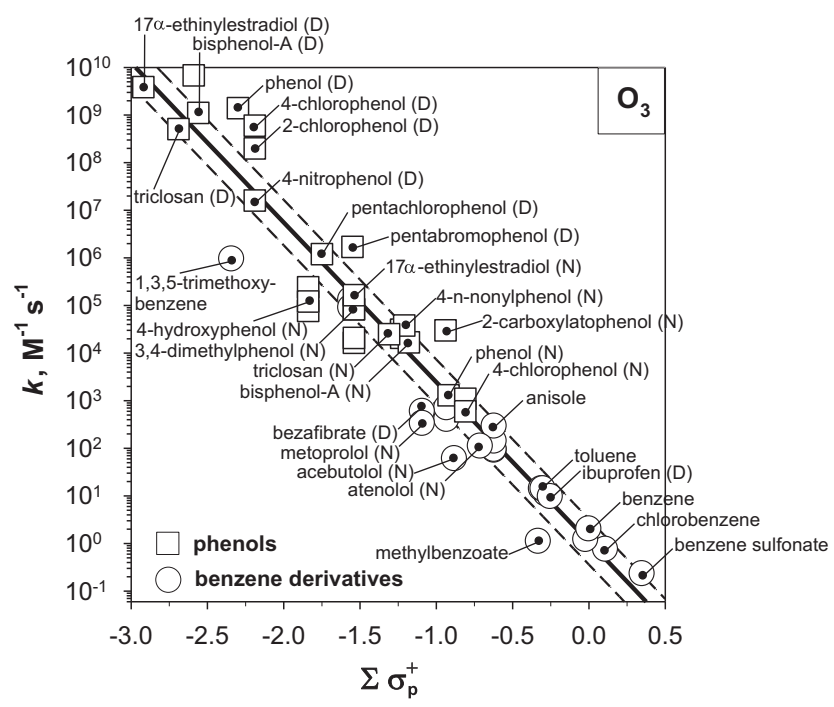

Fig. 7 - Correlation between the second-order rate constants $(k)$ for the reactions of $\mathrm{O}_{3}$ with benzene derivatives (e.g. phenols, alkylbenzenes etc) vs. $\sum \sigma_{p}^{+}$ (Eq. (13), Table 1) which are determined using benzene as a reference compound instead of phenol (see main text for further explanation). ' $D$ ' and ' $N$ ' in parenthesis indicate 'dissociated' and 'non-dissociated' species, respectively. Some symbols are not named due to space limitation: dissociated phenols such as 4-n-nonyl-phenolate; nondissociated phenols such as 2-chloro-, 2-methyl-, 3methyl-, 4-methyl-, 2,3-dimethyl-, 2,4-dimethyl-, 2,6dimethyl-, 2-hydroxy- and 3-hydroxy-phenol, benzene derivatives such as 1,4-dimethoxy-, 3,4-dimethoxy-, ethyl-, isopropyl-, 1,2,3-trimethyl-, 1,3,5-trimethyl-benzene, and ortho-xylene, meta-xylene, para-xylene and benzoate (data, SI-EXCEL-1).

1/3-3. Eq. (13) can be useful to predict the $k$-values for the reaction of $\mathrm{O}_{3}$ with some benzene derivatives, such as alkyl-, alkoxy-, and halo-benzenes. For phenols, Eqs. (7) and (8) can be applied preferentially because they give better predictions than Eq. (13). Currently, the $k_{\mathrm{BZD}}$-values of $\mathrm{O}_{3}$ are known for several micropollutants. Eq. (13) predicts the $k_{\mathrm{BZD}}$-values with difference of less than a factor of 3 for atenolol/nondissociated and ibuprofen/dissociated. However, the predicted $\mathrm{k}_{\mathrm{BZD}}$-values for bezafibrate/dissociated, metoprolol/ non-dissociated and acebutolol/non-dissociated differ from the measured ones by a factor of 7.1, 12.6 and 13.7, respectively (see Fig. 7 and SI-Excel-1).

\subsubsection{Olefins}

Among the selective oxidants, only $\mathrm{O}_{3}$ and $\mathrm{HFeO}_{4}^{-}$show a reactivity towards olefins (e.g. $k>10 \mathrm{M}^{-1} \mathrm{~s}^{-1}$ ) while $\mathrm{ClO}_{2}$ and $\mathrm{HOCl}$ react very slowly with olefins (e.g. $k<1 \mathrm{M}^{-1} \mathrm{~s}^{-1}$ ). For $\mathrm{O}_{3}$, 74 rate constants are available while only two rate constants are known for $\mathrm{HFeO}_{4}^{-}$. Therefore, the correlation analysis was performed only for $\mathrm{O}_{3}$ (SI-Excel-1).

$\mathrm{O}_{3}$ (Fig. 8). Correlations based on the Hammett $\sigma$ constants turned out to be poor. Therefore, the Taft $\sigma^{*}$ constants were selected. The $k$-values for the reaction of $\mathrm{O}_{3}$ with nucleic acids and their constituents as olefin-containing compounds

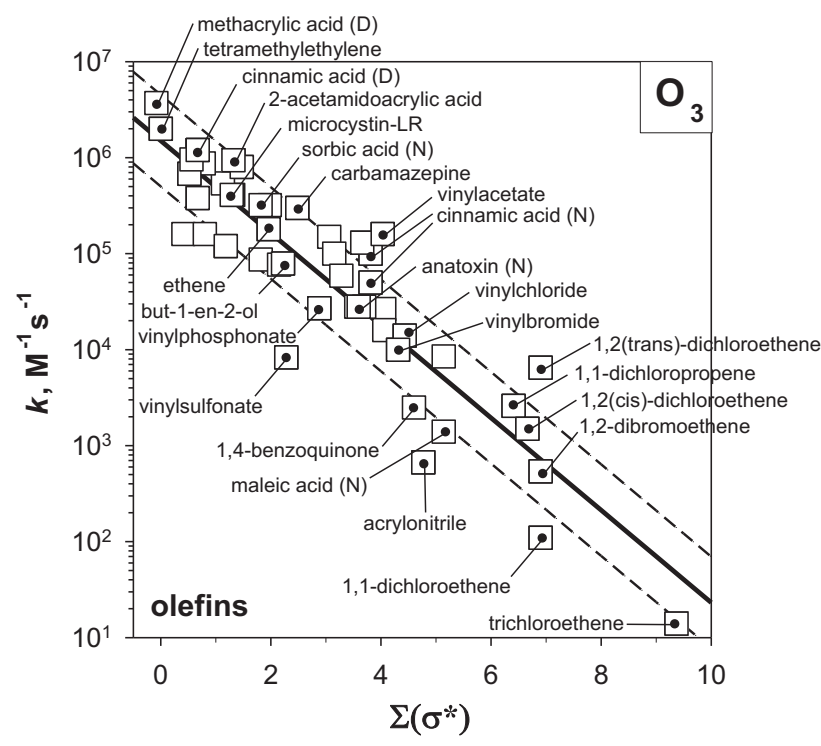

Fig. 8 - Correlation between the second-order rate constants $(k)$ for the reactions of $\mathrm{O}_{3}$ with olefins vs. $\sum \sigma^{*}$ (Eq. (14), Table 1). ' $D$ ' and ' $N$ ' in parenthesis indicate 'dissociated' and 'non-dissociated' species, respectively. Some symbols are not named due to space limitation: acrylamide, acrylic acid (D), acrylic acid (N), cephalexin (D), fumaric acid (N), cis-3-hexen-1-ol, methacrylic acid (N), $\beta$ ionone, 4-methoxy-cinnamic acid (D), cis-cis-muconic acid (N), trans-trans-muconic acid (N), 4-nitro-cinnamic acid (D), trans-cis-2,6-nonadienal, muconic acid (N), oseltamivir acid (D), 1-penten-3-one, propene, tylosin and vinylphosphonic acid (N) (data, SI-EXCEL-1).

(Theruvathu et al, 2001) were excluded in the QSAR analysis because their Taft $\sigma^{*}$ constants were difficult to calculate (due to heterocyclic structure). 12 out of $74 k$-values for the reaction of $\mathrm{O}_{3}$ could not be used because Taft $\sigma^{*}$ constants are not available for the substituents, such as, $m$-, $p$-dihydroxy-phenyl-, $-\mathrm{CH}=\mathrm{CH}-\mathrm{CO}_{2}^{-},-\mathrm{PO}_{3}^{2-},-\mathrm{PO}(\mathrm{OH})_{2}$ etc (see SI-Excel-1). In addition, 13 out of $74 k$-values were excluded as outliers because the predicted $k_{\text {olefin }}$-values differed significantly from the measured values by a factor of $>50$. These compounds typically contain carboxylate anion (e.g. maleic acid/dissociated) or cyclohexene with carbonyl (e.g. progesterone) as substituents (see SI-Excel1). Finally, $48 k$-values were used to develop Eq. (14) for the linear correlation of ozone for $k_{\text {olefin. }}$ (Table 1 and Fig. 8).

$\mathrm{O}_{3}$ shows a high reactivity towards olefins with electrondonating substituents (e.g. $k_{\text {olefin }}>10^{5} \mathrm{M}^{-1} \mathrm{~s}^{-1}$ for alkyl, alkoxy, and hydroxyl). However, with an increasing number of electron-withdrawing substituents such as halogens and carbonyls, the $k_{\text {olefin }}$-values decrease significantly with a $\rho$ slope of -0.49 . For example, the $k_{\text {olefin }}$-values of ozone with trichloroethene (TCE) and tetrachloroethene (PCE) are 140 and $<0.1 \mathrm{M}^{-1} \mathrm{~s}^{-1}$, respectively. 33 out of $48(69 \%) k_{\text {olefin }}$-values were predicted by Eq. (14) within a factor of 1/3-3. In addition to those halogenated alkenes, the $k_{\text {olefin-values }}$ with several olefin-containing micropollutants are available. The $k_{\text {olefin }}{ }^{-}$ values for anatoxin-a/non-dissociated, cephalexin/dissociated, cis-3-hexen-1-ol, microcystin-LR, trans-cis-2,6- 
nonadienal, oseltamivir acid/dissociated, 1-penten-3-one and tylosine were predicted with Eq. (14) within a factor of 1/3-3. However, the predicted $k_{\text {olefin }}$-value for carbamazepine and $\beta$ ionone differ from the measured values by a factor of 3.2 and 3.9, respectively (see SI-Excel-1).

$\mathrm{HFeO}_{4}^{-}$. The $k_{\text {olefin }}$-values for $\mathrm{HFeO}_{4}^{-}$reactions are available only for butenol $\left(k_{\text {olefin }}=19 \mathrm{M}^{-1} \mathrm{~s}^{-1}\right)$ and carbamazepine $\left(k_{\text {olefin }}=70\right.$ or $110 \mathrm{M}^{-1} \mathrm{~s}^{-1}$ ) ( $\mathrm{Hu}$ et al., 2009; Lee et al., 2009). Compared to the $k$-values for $\mathrm{HFeO}_{4}^{-}$reactions with phenolates and anilines (i.e. $k_{\mathrm{PhO}}$ and $k_{\mathrm{ArNH}}$ ), the $k_{\mathrm{olefin}}$-values are about two or three orders of magnitude lower.

\subsubsection{Amines}

Alkylamines have three sub-classes depending on the number of alkyl carbons attached to the nitrogen, i.e. primary $\left(1^{\circ}\right.$, $\left.\mathrm{RNH}_{2}\right)$, secondary $\left(2^{\circ}, \mathrm{R}_{2} \mathrm{NH}\right)$, and tertiary $\left(3^{\circ}, \mathrm{R}_{3} \mathrm{~N}\right)$ amines. Ammonia, hydroxylamine and halo-amines as inorganic amines are sub-classes of amines. There are also halogenatedalkylamines and amide. In this study, the $k$-values of all these sub-classes of amines with structures such as $R_{1}-N\left(R_{2}\right)-R_{3}(R$ : alkyl, carbonyl, hydrogen, and hydroxyl) were considered in the QSAR analysis. All selective oxidants are in general reactive to alkylamines. Exceptions are found for the reaction of $\mathrm{ClO}_{2}$ with $1^{\circ}$ and $2^{\circ}$ alkylamines and the reaction of $\mathrm{HFeO}_{4}^{-}$ with $3^{\circ}$ alkylamines, in which the $k_{\text {app }}$-values at near-neutral $\mathrm{pH}$ are typically $<10 \mathrm{M}^{-1} \mathrm{~s}^{-1}$. The selective oxidants are reactive to hydroxylamine but show much lower reactivity to ammonia, halo-amines, and amides. An exception for this is the fast reaction of $\mathrm{HOCl}$ with ammonia which forms chloramines $\left(\mathrm{HOCl}+\mathrm{NH}_{3} \rightarrow \mathrm{NH}_{2} \mathrm{Cl}+\mathrm{H}_{2} \mathrm{O}, \quad k=3 \times 10^{6} \mathrm{M}^{-1} \mathrm{~s}^{-1}\right.$, Deborde and von Gunten, 2008).

Taft $\sigma^{*}$ constants were used to develop QSARs for amines. Alkylamines typically have $\mathrm{pK}_{\mathrm{a}}$ values in the range of 9-11. Since N-protonated alkylamine moieties are not susceptible to oxidation, the reactivity is determined by the concentration of $\mathrm{N}$-deprotonated alkylamine species. Therefore, the corresponding rate constant, $k_{\text {amine, }}$ are typically known for deprotonated alkylamine species. For $\mathrm{O}_{3}, \mathrm{ClO}_{2}$, and $\mathrm{HOCl}$, a considerable number of $k$-values are available to develop QSARs. However, a limited number of $k$-values are available for the reaction of $\mathrm{HFeO}_{4}^{-}$with amines and thus reliable QSARs could not be obtained.

In the correlation analysis, all sub-classes of amines were considered together in the first step. When one class of amine showed significantly different $k_{\text {amine-values from the rest of }}$ the corresponding amine-class was excluded in the next round. This process was repeated until the best correlations were obtained.

$\mathrm{O}_{3}$ (Fig. 9). The linear correlation of ozone for $k_{\text {amine }}$ is shown in Eq. (15) in Table 1. Eq. (15) includes the $k_{\text {amine-values }}$ of not only $1^{\circ}, 2^{\circ}$, and $3^{\circ}$ alkylamines but also several inorganic amines such as hydroxylamine, chloramines and bromamines. $\mathrm{O}_{3}$ shows a high reactivity to $2^{\circ}$ and $3^{\circ}$ alkylamines:

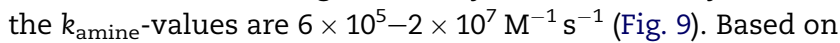
typical $\mathrm{pK}_{\mathrm{a}}$ values of $2^{\circ}\left(\mathrm{pK}_{\mathrm{a}} \sim 10\right)$ and $3^{\circ}$ alkylamines $\left(\mathrm{pK}_{\mathrm{a}}\right.$ of $\sim 9)$, the $k_{\mathrm{app}}$-values at $\mathrm{pH} 7$ are $60-2 \times 10^{5} \mathrm{M}^{-1} \mathrm{~s}^{-1}$. The $k_{\mathrm{app}}$ values will increase a factor of 10 per $\mathrm{pH}$ unit in the $\mathrm{pH}$ range

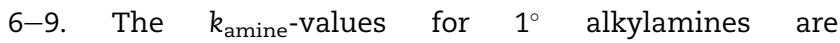
$5 \times 10^{4}-2 \times 10^{5} \mathrm{M}^{-1} \mathrm{~s}^{-1}$, which are about one or two orders of magnitude lower than those for $2^{\circ}$ and $3^{\circ}$ alkylamines (Fig. 9).

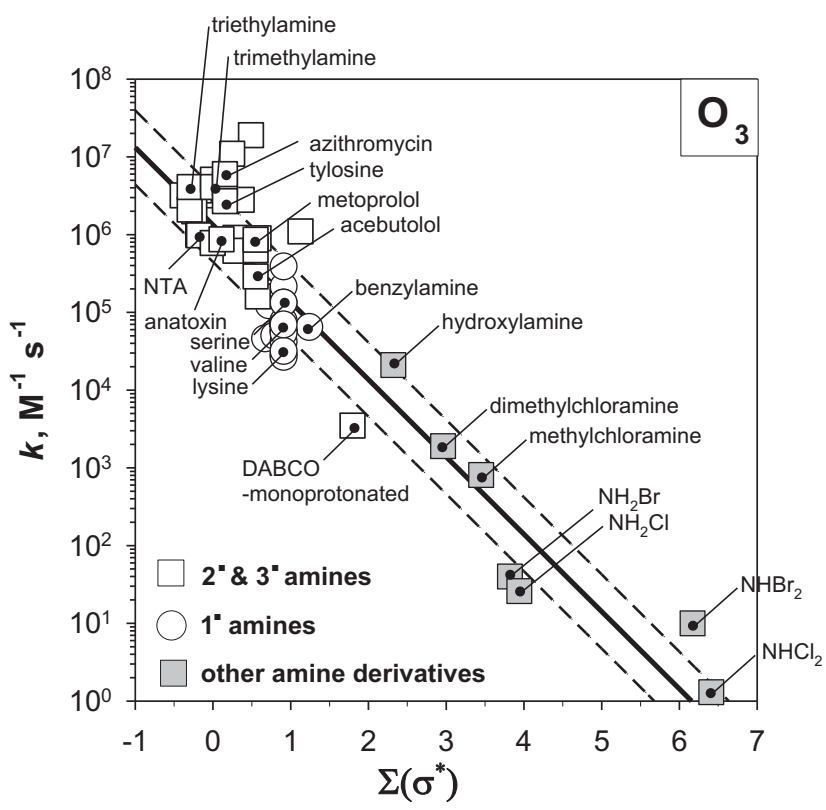

Fig. 9 - Correlation between the second-order rate constants $(k)$ for the reactions of $\mathrm{O}_{3}$ with amines \& amine derivatives vs. $\sum \sigma^{*}$ (Eq. (15), Table 1). Some symbols are not named due to space limitation: $2^{\circ} \& 3^{\circ}$ amines such as atenolol, ciprofloxacin, diethylamine, dimethylamine, $\mathrm{N}, \mathrm{N}$-dimethylcyclohexylamine, dimethylethanolamine, enrofloxacin, ethyl-N-piperazine carboxylate, EDTA, iminodiacetic acid, 1-methylpyrrolidine, roxithromycin and tramadol; $1^{\circ}$ amines such as alanine, arginine, aspartate, $n$-butylamine, sec-butylamine, tert-butylamine, cyclohexanemethylamine, cyclohexylamine, glutamine, glycine, isoleucine, leucine and phenylalanine (data, SIEXCEL-1).

The $k_{\text {app }}$-values at $\mathrm{pH} 7$ for $1^{\circ}$ alkylamines will then be $50-2 \times 10^{2} \mathrm{M}^{-1} \mathrm{~s}^{-1}$ by assuming the $\mathrm{pK}_{\mathrm{a}}$ of 10 for $1^{\circ}$ alkylamines. Among inorganic amines, hydroxylamine shows a high reactivity to $\mathrm{O}_{3}: k_{\text {amine }}=2.1 \times 10^{4} \mathrm{M}^{-1} \mathrm{~s}^{-1}$. However, haloamines such as $\mathrm{NH}_{2} \mathrm{Cl}$ and $\mathrm{NHCl}_{2}, \mathrm{NH}_{2} \mathrm{Br}$ and $\mathrm{NHBr}_{2}$ have a low reactivity to $\mathrm{O}_{3}$ (i.e. $k<40 \mathrm{M}^{-1} \mathrm{~s}^{-1}$ ). Ammonia, $\mathrm{N}, \mathrm{N}$ dimethylacetamide, N,N-dimethylformamide, and $\mathrm{N}, \mathrm{N}$ dimethylnitrosamine were not considered due to a much lower reactivity to $\mathrm{O}_{3}$ than the predictions made by Eq. (15) (see SI-Excel-1).

Eq. (15) predicts 33 out of 54 (61\%) $k_{\text {amine-values within }}$

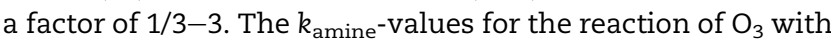
several amine-containing micropollutants are available (Fig. 9). The $k_{\text {amine-values for acebutolol, anatoxin-a (attack on }}$ the deprotonated amine, not on the double bond), atenolol, ciprofloxacin, DABCO, EDTA, EDTA-H ${ }^{+}$, enrofloxacin, metoprolol, NTA, tramadol and tylosine were predicted with a difference of less than a factor of 3 . However, the predicted

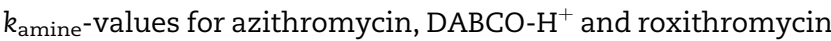
differ from the measured ones by a factor of 6.4, 6.2 and 4.8, respectively (see SI-Excel-1).

$\mathrm{ClO}_{2}$ (Fig. 10). For $\mathrm{ClO}_{2}$, two different correlations were established: one for the reaction with $3^{\circ}$ alkylamines and the 


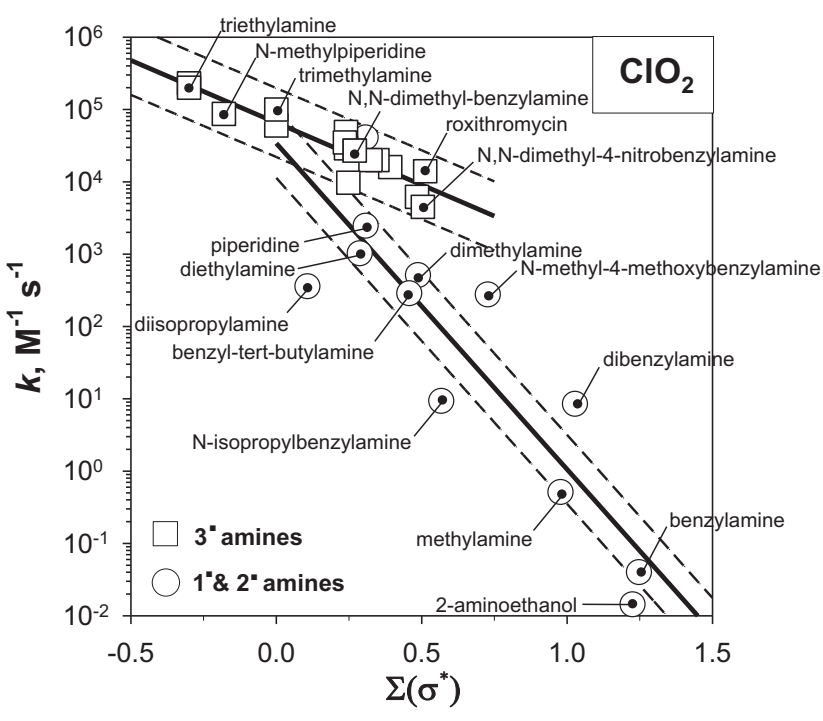

Fig. 10 - Correlation between the second-order rate constants $(k)$ for the reactions of $\mathrm{ClO}_{2}$ with $3^{\circ}$ alkylamines (Eq. (16), Table 1) and with $1^{\circ} \& 2^{\circ}$ alkylamines (Eq. (17), Table 1) vs. $\sum \sigma^{*}$. Some symbols are not named due to space limitation: $3^{\circ}$ alkylamines such as $\mathrm{N}, \mathrm{N}$-dimethyl-3chloro-, N,N-dimethyl-4-chloro-, N,N-dimethyl-4-fluoro-, N,N-dimethyl-3-methoxy-, N,N-dimethyl-4-methoxy-, $\mathrm{N}, \mathrm{N}$-dimethyl-4-methyl- and $\mathrm{N}, \mathrm{N}$-dimethyl-3-nitrobenzylamine, $\mathrm{N}, \mathrm{N}$-dimethyl-tert-butylamine and dimethylethanolamine (data, SI-EXCEL-1).

other with $1^{\circ} \& 2^{\circ}$ alkylamines, which are shown in Eqs. 16 and 17 in Table 1 , respectively. $\mathrm{ClO}_{2}$ shows a high reactivity to $3^{\circ}$ alkylamines: the $k_{3^{\circ} \text { amine }}$ values are $5 \times 10^{3}-2 \times 10^{5} \mathrm{M}^{-1} \mathrm{~s}^{-1}$ (Fig. 10). Based on typical $\mathrm{pK}_{\mathrm{a}}$ values of $3^{\circ}$ alkylamines $\left(\mathrm{p} \mathrm{K}_{\mathrm{a}}\right.$ $\sim 9)$, the $\mathrm{k}_{\mathrm{app}}$-values at $\mathrm{pH} 7$ for $3^{\circ}$ alkylamines are 50-2 $\times 10^{3} \mathrm{M}^{-1} \mathrm{~s}^{-1}$. In addition, the $k_{\mathrm{app}}$-values will increase by a factor of 10 per $\mathrm{pH}$ unit in the $\mathrm{pH}$ range $6-9$. In contrast, $\mathrm{ClO}_{2}$ shows a relatively low reactivity to $1^{\circ}$ and $2^{\circ}$ alkylamines. In addition, $k_{1^{\circ}} \& 2^{\circ}$ amine-values are significantly influenced by the substituent effect with a $\rho$ slope of -4.51 . The $k$-values with $2^{\circ}$ alkylamines, are $10-10^{4} \mathrm{M}^{-1} \mathrm{~s}^{-1}$. Considering a typical $\mathrm{pK}_{\mathrm{a}}$ of $2^{\circ}$ alkylamines $\left(\mathrm{pK}_{\mathrm{a}} \sim 10\right)$, the $k_{\mathrm{app}}$-values at $\mathrm{pH} 7$ for $2^{\circ}$ alkylamines are $10^{-2}-10 \mathrm{M}^{-1} \mathrm{~s}^{-1}$. The $k$-values with $1^{\circ}$ alkylamines are even below $1 \mathrm{M}^{-1} \mathrm{~s}^{-1}$. Therefore, most of $1^{\circ}$ and $2^{\circ}$ alkylamines react slowly with $\mathrm{ClO}_{2}$ in the $\mathrm{pH}$ range 6-9 (e.g. $k_{\text {app }}$-values at $\left.\mathrm{pH} 7<10 \mathrm{M}^{-1} \mathrm{~s}^{-1}\right)$. Eq. (16) predicts all 16

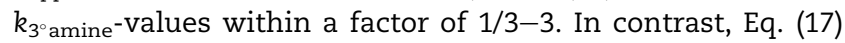
shows a poor correlation: only 6 out of $12(50 \%) k_{1^{\circ} \& 2^{\circ} \text { amine }^{-}}$ values were predicted within a factor of 1/3-3.

$\mathrm{HOCl}$ (Fig. 11). For HOCl, two different correlations were established: one for the reaction with $3^{\circ}$ alkylamines and the other with $1^{\circ}$ alkylamines and amine derivatives (haloamines and ammonia), which are shown in Eqs. 18 and 19 in Table 1, respectively. In contrast to the case of $\mathrm{O}_{3}$ and $\mathrm{ClO}_{2}, \mathrm{HOCl}$ shows a lower reactivity to $3^{\circ}$ alkylamines than $1^{\circ}$ and $2^{\circ}$ alkylamines (Fig. 11). Nevertheless, $\mathrm{HOCl}$ shows still a considerable reactivity to $3^{\circ}$ alkylamines $\left(k_{3^{\circ} \text { amine }}=10^{3}-10^{5} \mathrm{M}^{-1} \mathrm{~s}^{-1}\right)$. Therefore, the $k_{\text {app }}$-values at $\mathrm{pH} 7$ for $3^{\circ}$ alkylamines are $10-10^{3} \mathrm{M}^{-1} \mathrm{~s}^{-1}$ based on a typical $\mathrm{pK}_{\mathrm{a}}$ value of $3^{\circ}$ alkylamines $\left(\mathrm{pK}_{a} \sim 9\right)$. The

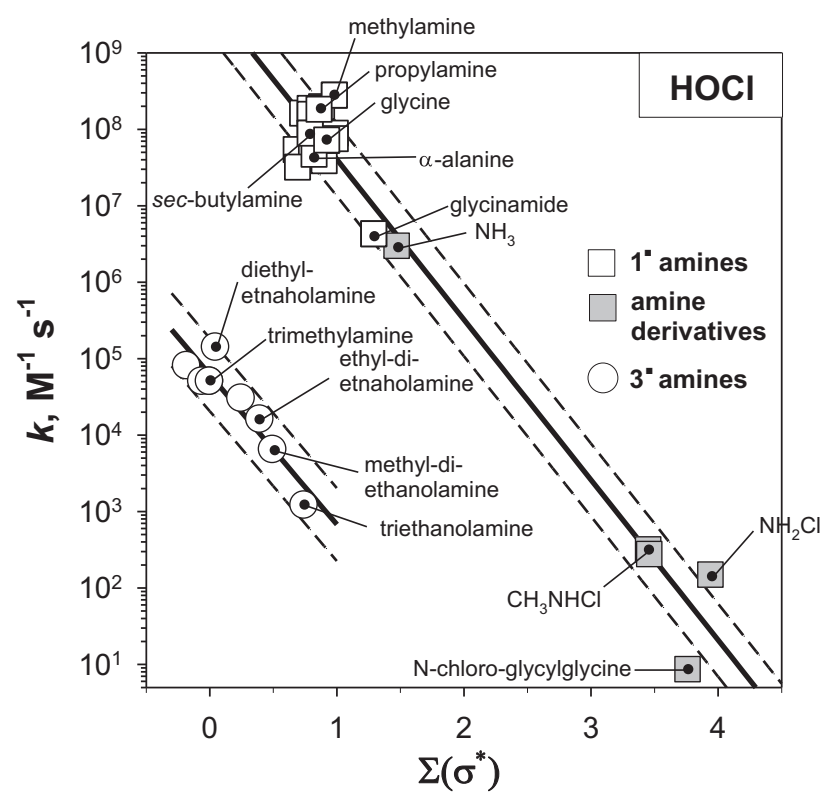

Fig. 11 - Correlation between the second-order rate constants $(k)$ for the reactions of $\mathrm{HOCl}$ with $3^{\circ}$ alkylamines (Eq. (18), Table 1) and with $1^{\circ}$ alkylamines and amine derivatives (halo-amines and ammonia) vs. $\sum \sigma^{*}$ (Eq. (19), Table 1). Some symbols are not named due to space limitation: $3^{\circ}$ alkylamines such as dimethylethanolamine, $\mathrm{N}, \mathrm{N}$-dimethylglycine and ( $\mathrm{N}$-methyl)-piperidine, $\mathbf{1}^{\circ}$ alkylamines such as $\beta$-alanine, 2-amino-, 3-amino- and 4amino-butyric acid, 3-amino-iso-butyric acid, 2-aminohexanoic acid, $n$-butylamine, iso-butylamine, tertbutylamine, ethylamine and iso-propylamine, amine derivatives such as $\mathrm{N}$-chloro- $\beta$-alanine.

reactivity of $\mathrm{HOCl}$ toward $1^{\circ}$ and $2^{\circ}$ alkylamines is very high $\left(k_{1^{\circ} \text { amine }}\right.$ and $\left.k_{2^{\circ} \text { amine }}=4 \times 10^{6}-3 \times 10^{8} \mathrm{M}^{-1} \mathrm{~s}^{-1}\right)$. Based on typical $\mathrm{pK}_{\mathrm{a}}$ of $1^{\circ}$ and $2^{\circ}$ alkylamines $\left(\mathrm{pK}_{\mathrm{a}} \sim 10\right)$, the $k_{\mathrm{app}}$-values at $\mathrm{pH} 7$ for $1^{\circ}$ and $2^{\circ}$ alkylamines are $4 \times 10^{3}-3 \times 10^{5} \mathrm{M}^{-1} \mathrm{~s}^{-1}$. Poor correlations were found $\left(\mathrm{r}^{2}=0.03\right)$ when considering the

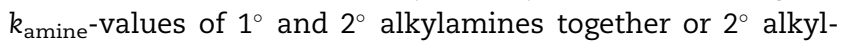
amine only. Therefore, $2^{\circ}$ amines were not considered for our correlations. Instead, a good correlation (i.e. Eq. (19)) was found

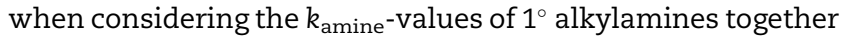
with those of halo-amines and ammonia (Fig. 11).

Eq. (18) predicts all eight $k_{3^{\circ} \text { amine }}$-values within a factor of

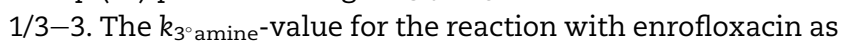
$3^{\circ}$ alkylamine-containing micropollutant has been determined to be $1.6 \times 10^{3} \mathrm{M}^{-1} \mathrm{~s}^{-1}$ (Dodd et al., 2005), which differs from the predicted value by a factor of 40 (see SI-Excel-1). Therefore, it was not included in developing Eq. (18) (see SIExcel-1). Eq. (19) predicts 17 out of 22 (77\%) $k_{1}{ }^{\circ}$ amine-values within a factor of $1 / 3-3$. Even though good correlations were not found for $2^{\circ}$ alkylamines, their $k$-value are typically in the range of $10^{7}-10^{8} \mathrm{M}^{-1} \mathrm{~s}^{-1}$ (see SI-Excel-1). In accordance with this, the $k$-value for the reaction with ciprofloxacin, a $2^{\circ}$ alkylamine-containing micropollutant is $4.9 \times 10^{7} \mathrm{M}^{-1} \mathrm{~s}^{-1}$ (Dodd et al., 2005).

$\mathrm{HFeO}_{4}^{-}$. The number of determined rate constants for the reaction of $\mathrm{HFeO}_{4}^{-}$with amines is limited. Less than $10 k$ - 
values are currently known for some alkylamines and inorganic amine species (Lee et al., 2008, 2009; Noorhasan et al., 2010; Zimmermann et al., 2012). No clear correlations were found among these $k$-values. Some simple calculations were performed to give rough estimates of $k$-values for the reaction of $\mathrm{HFeO}_{4}^{-}$with amines. The $k$-values for the reaction with $3^{\circ}$ alkylamines are $2 \times 10^{2}-1 \times 10^{3} \mathrm{M}^{-1} \mathrm{~s}^{-1}$. With typical $\mathrm{pK}$ values of $3^{\circ}$ alkylamines $\left(\mathrm{pK}_{\mathrm{a}} \sim 9\right)$, the $\mathrm{k}_{\mathrm{app}}$-values at $\mathrm{pH} 7$ for $3^{\circ}$ alkylamines are estimated to be $2-10 \mathrm{M}^{-1} \mathrm{~s}^{-1}$. The $k$-values for the reaction with $2^{\circ}$ alkylamines are $4.4 \times 10^{3}$ and $1.8 \times 10^{4} \mathrm{M}^{-1} \mathrm{~s}^{-1}$ for ciprofloxacin and dimethylamine, respectively, which are about one order of magnitude higher than those for $3^{\circ}$ alkylamines. With typical $\mathrm{pK}_{\mathrm{a}}$ values of $2^{\circ}$ amines $\left(\mathrm{pK}_{\mathrm{a}} \sim 10\right)$, the $k_{\mathrm{app}}$-values at $\mathrm{pH} 7$ for $2^{\circ}$ amines are estimated to be $4.4-18 \mathrm{M}^{-1} \mathrm{~s}^{-1}$. However, the $k_{\mathrm{app}}$-values at $\mathrm{pH}$ 7 for ciprofloxacin and enrofloxacin are rather high due to the low $\mathrm{pK}_{\mathrm{a}}$ values of these two cyclic amine moieties $\left(\mathrm{pK}_{\mathrm{a}}=7.7\right.$ and 8.8 , respectively). Finally, the $k$-value for the reaction with $1^{\circ}$ alkylamines (i.e. glycine) was determined as $3.0 \times 10^{4} \mathrm{M}^{-1} \mathrm{~s}^{-1}$ (Noorhasan et al., 2010).

\subsubsection{Cross-correlations}

Rate constants for the reactions of oxidants can be used as descriptor variables in correlation analysis (Canonica and Tratnyek, 2003; Deborde and von Gunten, 2008). Fig. 12 shows two developed correlations between the logarithm of $k$-values for the reaction of $\mathrm{O}_{3}$ vs. $\mathrm{ClO}_{2}$ (Fig. 12a) and $\mathrm{O}_{3}$ vs. $\mathrm{HOCl}$ (Fig. 12b) with various aromatic compounds. The aromatic compounds include mostly phenols (dissociated and non-dissociated) but also some anilines (aniline, diclofenac, and sulfamethoxazole), alkoxybenzene (anisole), polycyclicaromatic (pyrene), and pyrimidine derivative (trimethoprim). Eqs. (20) and (21) are the resulting correlations for the reaction of $\mathrm{O}_{3}$ vs. $\mathrm{ClO}_{2}$ and $\mathrm{O}_{3} \mathrm{vs}$. $\mathrm{HOCl}$, respectively.

11 out of 16 (69\%) $k$-values were predicted by Eq. (20) within a factor of $1 / 3-3.13$ out of $24(54 \%) k$-values were predicted by Eq. (21) within a factor of 1/3-3. For diclofenac and sulfamethoxazole, the $k$-values for the reaction with both $\mathrm{O}_{3}$ and $\mathrm{ClO}_{2}$ are known, therefore Eq. (20) could be tested to predict these $k$-values. The result shows that Eq. (20) predicts these two $k$ values with differences of less than a factor of 3 (Fig. 12a). In the case of Eq. (21), the $k$-values for the reaction of $\mathrm{O}_{3}$ and $\mathrm{HOCl}$ were correlated with differences of less than a factor of 3 for the following four micropollutants: steroid estrogens (17 $\alpha$-ethinylestradiol, 17 $\beta$-estradiol, estrone, and estriol/dissociated bisphenol-A/dissociated, steroid estrogens/non-dissociated, and 4-n-nonylphenol/non-dissociated. However, for the other micropollutants, Eq. (21) predicts the k-values poorly: the predicted $k$-values differ from the measured ones by a factor of 4.7 for 4-n-nonylphenol/dissociated, 4.4 for triclosan/dissociated, 44 for sulfamethoxazole, 7.6 for trimethoprim/fully dissociated, and 3.3 for bisphenol-A/non-dissociated (Fig. 12b). Eqs. (20) and (21) can be useful for predicting $k$-values of aromatic compounds when the $k$-value of at least one oxidant is known. However, because the correlations are derived mainly based on phenols, they should be cautiously applied to other nonphenolic aromatic compounds, such as anilines and polycyclic aromatic compounds.

\subsection{Estimation methods of k-values for $\mathrm{HO}^{\bullet}$ reactions}

This section will briefly introduce some principles and estimation methods for $\mathrm{HO}^{\bullet}$ reaction rate constants. $\mathrm{HO}^{\bullet}$ react with organic compounds primarily in four ways: (1) by addition to an olefin or an aromatic system, (2) by abstraction of a hydrogen atom from a carbon atom, (3) electron transfer reactions and (4) by reaction with sulfur-, nitrogen-, or phosphorus-moieties (Buxton et al., 1988; Minakata et al., 2009; Schwarzenbach et al., 2003). Currently, there are a few thousands $k$-values available for the reaction of $\mathrm{HO}^{\bullet}$ with organic compounds. These $k_{\mathrm{HO}}$-values show that nearly diffusioncontrolled values (i.e. $k_{\mathrm{HO}}=3 \times 10^{9}-10^{10} \mathrm{M}^{-1} \mathrm{~s}^{-1}$ ) are observed for compounds containing 1) aromatic rings or olefins with electron-donating or even weakly-electron-withdrawing substituents, 2) aliphatic groups with multiple $\mathrm{H}$-atoms which can be easily abstracted, and 3) organic sulfur- or aminemoieties (Buxton et al., 1988). Many of the emerging organic micropollutants fulfill the above-described criteria, and
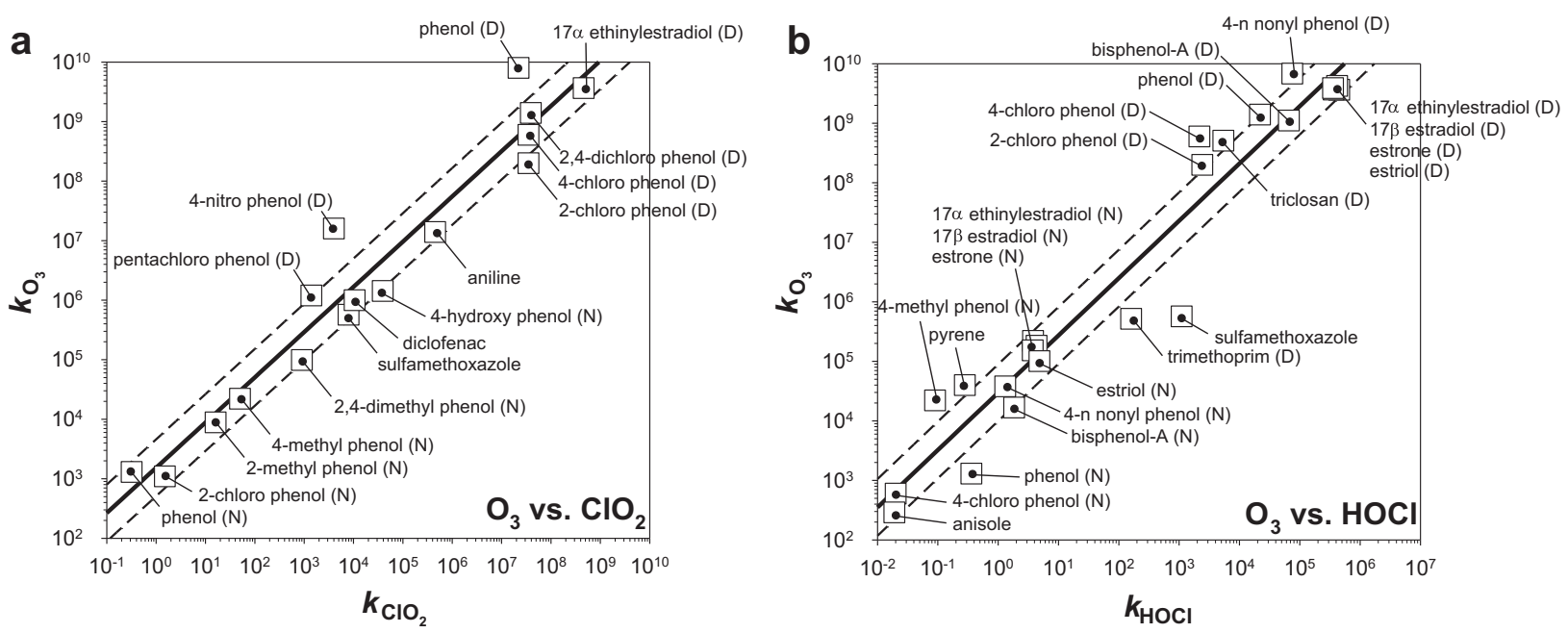

Fig. 12 - Linear cross correlations for selected aromatic compounds (mostly phenols) between (a) $\log k_{\text {aromatic }}\left(\mathrm{O}_{3}\right)$ and $\log k_{\text {aromatic }}\left(\mathrm{ClO}_{2}\right)$ (Eq. (20), Table 1) and (b) $\log k_{\text {aromatic }}\left(\mathrm{O}_{3}\right)$ and $\log k_{\text {aromatic }}(\mathrm{HOCl})$ (Eq. (21), Table 1). ' $\mathrm{D}$ ' and ' $N$ ' in parenthesis indicate 'dissociated' and 'non-dissociated' species, respectively (data, SI-EXCEL-1). 
consistent with this fact, the $k_{\mathrm{HO}}$-values for most emerging micropollutants have been known to be $\geq 3 \times 10^{9} \mathrm{M}^{-1} \mathrm{~s}^{-1}$ (see Table 2 for examples). Organic micropollutants that show a low reactivity to $\mathrm{HO}^{\circ}$ (i.e. $k_{\mathrm{HO}}<3 \times 10^{9} \mathrm{M}^{-1} \mathrm{~s}^{-1}$ ) are typically small sized (e.g. $\mathrm{MW}<200 \mathrm{Da}$ ) and contain electron-withdrawing substituents in their saturated carbon skeletons. These include methyl tert-butyl ether (MTBE, $k_{\mathrm{HO}}=1.9 \times 10^{9} \mathrm{M}^{-1} \mathrm{~s}^{-1}$ ), chloroform $\left(k_{\mathrm{HO}}=5 \times 10^{7} \mathrm{M}^{-1} \mathrm{~s}^{-1}\right)$, and $\mathrm{N}$-nitrosodimethylamine (NDMA, $k_{\mathrm{HO}}=4.5 \times 10^{8} \mathrm{M}^{-1} \mathrm{~s}^{-1}$ ) (Buxton et al., 1988, Lee et al., 2007). Therefore, as a rule of thumb, most emerging organic micropollutants with molecular sizes larger than 200 Da containing ERMs, will show $k_{\mathrm{HO}}$-values in the range of $3 \times 10^{9}-10^{10} \mathrm{M}^{-1} \mathrm{~s}^{-1}$, varying by a factor of $\sim 3$.

In addition to the aforementioned simple estimation method for $\mathrm{HO}^{\bullet}$ rate constants, there have been a few more sophisticated estimation methods for $\mathrm{HO}^{\bullet}$ rate constants. One of these methods is based on the group contribution method (GCM) which has been traditionally developed for predicting gas-phase $\mathrm{HO}^{\bullet}$ reaction rate constants (Minakata et al., 2009; Schwarzenbach et al., 2003). In the GCM method, the HO${ }^{\circ}$ reaction rate constant is determined by the reaction mechanism and effect of the neighboring functional group. As the reaction mechanism, it considers: (1) H-atom abstraction from $\mathrm{C}-\mathrm{H}$; (2) $\mathrm{HO}^{\bullet}$ addition to olefins; (3) $\mathrm{HO}^{\bullet}$ addition to aromatic rings; and (4) reaction with $\mathrm{N}-$, $\mathrm{P}-$, and $\mathrm{S}$-containing moieties. For each of these reaction mechanisms, there are 'group rate constants' which represent the reactivity of a reference reaction and 'group contribution factors' which represent the effect of neighboring functional groups on the reactivity of a reference reaction. Minakata et al (2009) reported 66 group rate constants and 80 substituent factors for these four reaction mechanisms, which were determined based on 310 $k_{\mathrm{HO}}$-values (Minakata et al., 2009). For $\mathrm{H}$-abstraction as an example, there exist three group rate constants with primary$\left(\mathrm{CH}_{3} \mathrm{R}_{1}, \quad k_{\text {prim }}=1.18 \times 10^{8} \mathrm{M}^{-1} \mathrm{~s}^{-1}\right)$, secondary- $\left(\mathrm{CH}_{2} \mathrm{R}_{1} \mathrm{R}_{2}\right.$, $\left.k_{\text {sec }}=5.11 \times 10^{8} \mathrm{M}^{-1} \mathrm{~s}^{-1}\right)$ and tertiary- C-H bonds $\left(\mathrm{CHR}_{1} \mathrm{R}_{2} \mathrm{R}_{3}\right.$, $\left.k_{\text {tert }}=19.9 \times 10^{8} \mathrm{M}^{-1} \mathrm{~s}^{-1}\right)$. The overall $\mathrm{H}$-atom abstraction rate constant, $k_{\mathrm{HO}}$ ( $\mathrm{H}$-abstr) can then be obtained from the sum of these partial rate constants (Eq. (22)):

$$
\begin{aligned}
k_{\mathrm{HO}} \cdot(\mathrm{H}-\text { abstr })= & 3 \sum k_{\text {prim }} \mathrm{X}_{\mathrm{R} 1}+2 \sum k_{\mathrm{sec}} \mathrm{X}_{\mathrm{R} 1} \mathrm{X}_{\mathrm{R} 2} \\
& +\sum k_{\text {tert }} \mathrm{X}_{\mathrm{R} 1} \mathrm{X}_{\mathrm{R} 2} \mathrm{X}_{\mathrm{R} 3}
\end{aligned}
$$

where $\mathrm{X}_{\mathrm{R} 1}, \mathrm{X}_{\mathrm{R} 2}$, and $\mathrm{X}_{\mathrm{R} 3}$ are the group contribution factors for $R_{1}, R_{2}$ and $R_{3}$ substituents, respectively. Finally, the total rate constant, $k_{\mathrm{HO}}$ (total), can be expressed by the sum of four rate constants as shown in Eq. (23):

$$
\begin{aligned}
k_{\mathrm{HO}}(\text { total })= & k_{\mathrm{HO}}(\mathrm{H}-\text { abstr })+k_{\mathrm{HO}}(\text { olefin })+k_{\mathrm{HO}}(\mathrm{Ar}) \\
& +k_{\mathrm{HO}}(\mathrm{NPS})
\end{aligned}
$$

where $k_{\mathrm{HO}}$ (H-abstr), $k_{\mathrm{HO}}$ (olefin), $k_{\mathrm{HO}}(\mathrm{Ar})$, and $k_{\mathrm{HO}}$ (NPS) are the rate constants for the aforementioned mechanisms, 1-4, respectively.

\subsection{Prediction of $\mathrm{k}$-values for the reaction of selective oxidants and $\mathrm{HO}^{\circ}$ with micropollutants}

As a demonstration, the QSARs from this study were used to predict $k$-values for the reaction of the selective oxidants with overall 16 selected micropollutants. In the case of $\mathrm{HO}^{\circ}$, the group contribution method developed by Minakata et al (2009) was used to estimate the $k$-values. The selected micropollutants include five phenolic- (acetaminophen, bisphenolA, $17 \alpha$-ethinylestradiol, 4-n-nonylphenol, and triclosan), two aniline- (sulfamethoxazole and diclofenac), three olefin(anatoxin/non-dissociated, carbamazepine, and microcystinLR), and four amine-containing compounds (anatoxin/dissociated, ciprofloxacin, enrofloxacin, and roxithromycin). In addition, gemfibrozil and naproxen were included as substituted benzenes. Therefore, the selected micropollutants cover a range of ERMs which are the site of attack by oxidants. These micropollutants were also chosen based on their environmental relevance. They are mostly pharmaceuticals and hormones which are discharged from municipal wastewater effluents. In addition, anatoxin and microcystin-LR may be produced during algal blooms.

Table 2 summarizes the predicted $k$-values and compares them with the measured ones if data are available. For the selective oxidants, 39 out of the 45 (87\%) predicted $k$-values were within a factor of $1 / 3-3$. The prediction of $k$-values was also applied to other emerging micropollutants which are not listed in Table 2 (see SI-Excel-1). Overall, 75 out of the 97 (77\%) predicted $k$-values were within a factor of $1 / 3-3$. It should be noted that since all measured $k$-values were already included in developing QSARs for the selective oxidants, the comparison between the measured and predicted values just confirms again the goodness of the calibration. For $\mathrm{HO}^{\circ}$, the GCM method predicts the $k$-values within a factor of $1 / 2-2$. One exception was the reaction of $\mathrm{HO}^{\bullet}$ with anatoxin-a. Its $k$ value was predicted to be $\sim 10^{10} \mathrm{M}^{-1} \mathrm{~s}^{-1}$, which is 3.3 times higher than the measured value $\left(k=3 \times 10^{9} \mathrm{M}^{-1} \mathrm{~s}^{-1}\right.$, Onstad et al., 2007). Finally, 29 new $k$-values were predicted for the reaction of selective oxidants and $\mathrm{HO}^{\bullet}$ (Table 2 ), which will be useful in estimating the elimination of these micropollutants during oxidative water treatment.

\subsection{Uncertainty in predicting micropollutant elimination by QSARs}

In this study, 18 QSARs were developed based on $412 k$-values for the reaction of the selective oxidants with (mostly) organic compounds containing various ERMs. 217 and 303 out of 412 (53 and $74 \%$ ) $k$-values were predicted within a factor of $1 / 2-2$ and $1 / 3-3$, respectively (see SI-Excel-1). In addition, the GCM method for $\mathrm{HO}^{\bullet}$ reaction showed a prediction of $k$-values within 1/2-2 (Minakata et al., 2009; see also Table 2). Therefore, as a rule of thumb, the $k$-values predicted by these QSARs have a potential error of a factor of up to 9, which is also commonly found in experimentally determined $k$-values.

Since we are interested in using $k_{\mathrm{app}}$-values to predict micropollutant elimination during oxidative water treatment, it is of interest to know how the uncertainty in the calculated $k$-values affects the prediction of elimination rates. For this, Eq. (3) was used to calculate the uncertainty propagation from ' $k_{\text {app }}$-value' to 'elimination'. In the first step, the \% elimination of micropollutant, $\mathrm{P}$ (i.e. $\left.\left(1-[\mathrm{P}] /[\mathrm{P}]_{\mathrm{O}}\right) \times 100\right)$ was calculated as a function of oxidant exposure by using a certain $k_{\text {app }}$-value. In the next step, the \% P elimination was calculated using the same oxidant exposure but with $k_{\mathrm{app}}$-values that were three- 
fold larger or smaller than before (i.e. $3 k_{\mathrm{app}}$ - or $1 / 3 k_{\mathrm{app}}$-values). Fig. 13a shows the calculated results. The uncertainty in the predicted \% P elimination can be defined as the difference of $\left(1-[\mathrm{P}] /[\mathrm{P}]_{0}\right) \times 100$ values obtained using $3 k_{\mathrm{app}^{-}}$and $1 / 3 k_{\mathrm{app}}{ }^{-}$ values. For example, the length of arrows in Fig. 13a represents the uncertainty at various levels of \% $\mathrm{P}$ elimination. Fig. $13 \mathrm{~b}$ shows the uncertainty in the predicted $\% \mathrm{P}$ elimination as a function of the $\% \mathrm{P}$ elimination levels. When the \% $\mathrm{P}$ elimination is less than $10 \%$ or higher than $99 \%$, the uncertainty is lower than $24 \%$. In other words, even when the predicted $k_{\text {app}}$-value has uncertainty of a factor of 9, micropollutant eliminations can be still predicted with less than $24 \%$ error. However, when the \% P elimination is in between $10 \%$ and $99 \%$, the uncertainty can be higher than $24 \%$. The largest uncertainty (i.e. $68 \%$ ) is observed when the $\%$ $\mathrm{P}$ elimination is $57 \%$ (Fig. 13b).

Based on the above exercise, the QSARs developed for the selective oxidants are good enough to estimate micropollutant elimination, especially for the cases of high or low micropollutant eliminations. This means that when predicting high or low $k_{\text {app}}$-values, there is potentially low uncertainty (e.g. <24\%) in the predicted levels of micropollutant elimination. The exact magnitude of $k_{\mathrm{app}}$-values in this
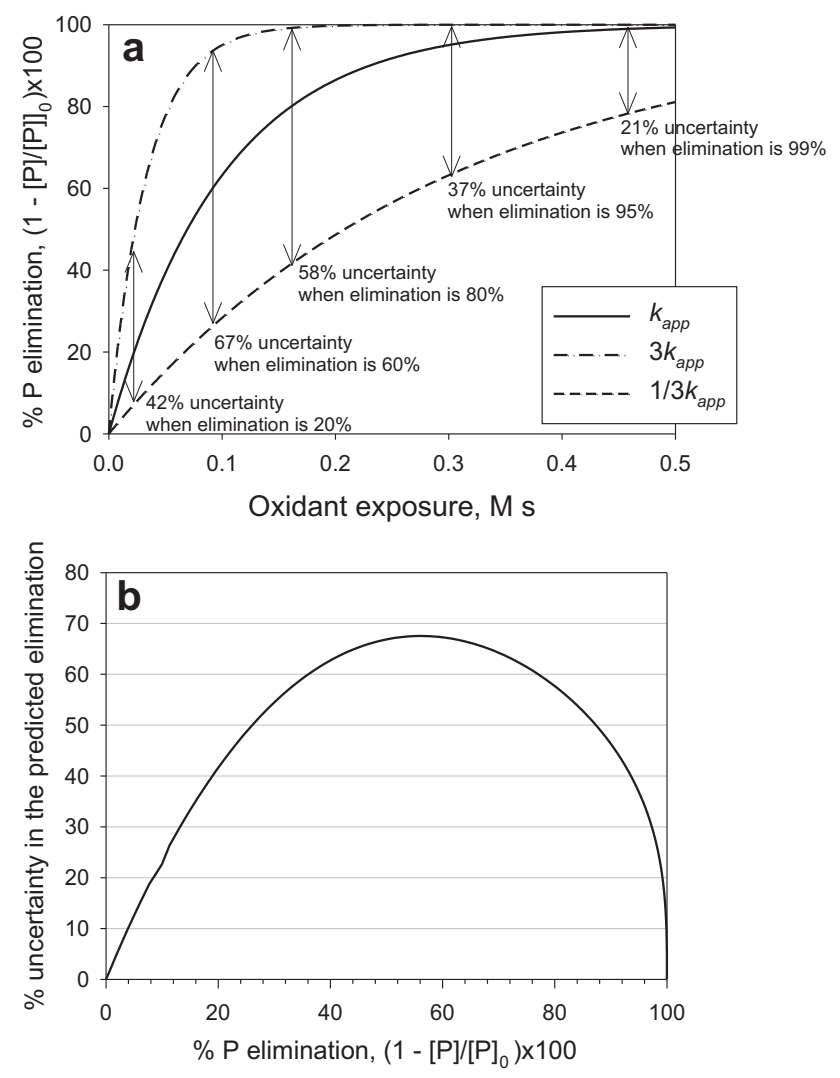

Fig. 13 - (a) Predicted \% elimination of micropollutant as a function of oxidant exposure using three different $k_{\text {app }}-$ values such as $k_{\mathrm{app}}, 3 k_{\mathrm{app}}$ and $1 / 3 k_{\mathrm{app}}\left(k_{\mathrm{app}}=10 \mathrm{M}^{-1} \mathrm{~s}^{-1}\right.$ was applied for calculations), the arrows represent the \% uncertainty in the predicted $P$ elimination (i.e. $\{\%$ elimination at $\left.3 k_{\text {app }}\right\}-\left\{\%\right.$ elimination at $\left.\left.1 / 3 k_{\text {app }}\right\}\right)$ and (b) $\%$ uncertainty in the predicted $P$ elimination as a function of $\%$ P elimination. criterion depends on the type of the selective oxidant and application. During ozonation of secondary wastewater effluents for example, micropollutants having $k_{\text {app }}$-values for the reaction with $\mathrm{O}_{3}$ higher than $10^{4} \mathrm{M}^{-1} \mathrm{~s}^{-1}$ are eliminated typically $>99 \%$ at $\mathrm{O}_{3}$ dose/DOC of higher than 0.6 (mass ratio) (Lee and von Gunten, 2010; Zimmermann et al., 2011). In addition, micropollutants having $k_{\text {app }}$-values less than $10 \mathrm{M}^{-1} \mathrm{~s}^{-1}$ are eliminated $<10 \%$ by $\mathrm{O}_{3}$ alone for the same experimental conditions (without considering the oxidation by $\mathrm{HO}^{\circ}$ ). Therefore, for these high or low $k_{\mathrm{app}}$-values, a factor of 9 uncertainty in the predicted $k_{\text {app }}$-values results in less than $24 \%$ uncertainty in predicted eliminations. However, for the intermediate $k_{\text {app}}$-values, the predicted eliminations will have potential uncertainty of up to $68 \%$.

In the case of $\mathrm{HO}^{\circ}$, the situation is different from the selective oxidants. In $\mathrm{UV} / \mathrm{H}_{2} \mathrm{O}_{2}$ treatment of secondary wastewater effluent for example, eliminations of most micropollutants remain 10-90\% at typical treatment conditions (e.g. UV dose $=300-700 \mathrm{~mJ} \mathrm{~cm}^{-2}$ and $\mathrm{H}_{2} \mathrm{O}_{2}=10-20 \mathrm{mgL}^{-1}$ ) (Lee and von Gunten, 2010; Rosario-Ortiz et al., 2010). This relatively low elimination efficiency of micropollutants during treatment by $\mathrm{HO}^{\bullet}$ is due to the significant scavenging of $\mathrm{HO}^{\bullet}$ by water matrices (e.g. dissolved organic matter and carbonate) (Lee and von Gunten, 2010). Therefore, uncertainty in predicted micropollutant elimination can be high by uncertainty in $k$ values based on the discussion above. However, the uncertainty in $k$-values estimated by the GCM method (a factor of 4) is smaller than those by the QSARs for selective oxidants (a factor of 9).

\section{Conclusions}

- 18 QSARs were developed for the reaction of selective oxidants $\left(\mathrm{O}_{3}, \mathrm{ClO}_{2}, \mathrm{HOCl}\right.$, and $\left.\mathrm{HFeO}_{4}^{-}\right)$with organic compounds containing various ERMs. 6 QSARs could be established for the reaction of $\mathrm{O}_{3}$ with phenols, phenolates, anilines, benzene derivatives, olefins, and amines based on $203 k$-values. 5 QSARs could be established for the reaction of $\mathrm{ClO}_{2}$ with phenols, phenolates, anilines, $3^{\circ}$ amines and $1^{\circ}$ $\& 2^{\circ}$ amines based on $79 k$-values. 3 QSARs could be established for the reaction of $\mathrm{HOCl}$ with phenolates, $3^{\circ}$ amines and $1^{\circ}$ amines based on $65 k$-values. 2 QSARs could be established for the reaction of $\mathrm{HFeO}_{4}^{-}$with phenols and phenolates based on $25 \mathrm{k}$-values. In addition, 2 crosscorrelations were established between the logarithm $k$ values for the reaction of $\mathrm{O}_{3}$ vs. $\mathrm{ClO}_{2}$ and $\mathrm{O}_{3} \mathrm{vs}$. $\mathrm{HOCl}$ with aromatic compounds based on $40 \mathrm{k}$-values. 303 out of 412 (74\%) $k$-values were predicted by the developed QSARs within a factor of 1/3-3 compared to the measured values. This level of uncertainty in $k$-values obtained from the QSAR predictions is comparable to the uncertainty in experimentally determined $k$-values.

- The established QSARs can be used to predict the $k$-values for emerging micropollutants and assess their transformation potential during oxidative water treatment. This could be demonstrated for 16 selected micropollutants that contain ERMs and have environmental relevance: 39 out of the $45(87 \%)$ predicted $k$-values were found to be within a factor $1 / 3-3$ compared to the measured values. 
- Uncertainty in the predicted $k$-values by the QSARs can cause uncertainty in the prediction of micropollutant elimination during oxidative water treatment. At a factor of 9 variance in the predicted $k$-values, the predicted micropollutant elimination will have less than $24 \%$ uncertainty when the \% micropollutant elimination is high (i.e. $>99 \%$ ) or low (i.e. $<10 \%$ ). However, when the elimination is in intermediate range (i.e. $10-90 \%$ ), the uncertainty in predicted micropollutant elimination can increase up to $68 \%$.

\section{Acknowledgements}

This study was supported by the Swiss Federal Offices for the Environment (Contract No. 07.0142.PJ/I232-2755), and the Basic Science Research Program through the National Research Foundation of Korea (NRF) funded by the Ministry of Education, Science and Technology (2012R1A1A1010985). The authors thank Silvio Canonica for reviewing the manuscript and helpful comments.

\section{Appendix A. Supplementary material}

Supplementary material associated with this article can be found, in the online version, at http://dx.doi.org/10.1016/j. watres.2012.06.006

\section{R E F E R E N C E S}

Albert, A., Serjeant, E.P., 1984. The Determination of Ionization Constants: A Laboratory Manual, third ed. Chapman \& Hall, New York.

Asano, T., Burton, F.L., Leverenz, H.L., Tsuchihashi, R., Tchobanoglous, G., 2007. Water Reuse: Issues, Technologies, and Applications, first ed. McGraw-Hill, New York.

Black \& Veatch Corporation, 2010. White's Handbook of Chlorination and Alternative Disinfectants, fifth ed. John Wiley \& Sons, Inc, Hoboken, New Jersey.

Buxton, G.V., Greenstock, C.L., Helman, W.P., Ross, W.P., 1988. Critical review of rate constants for reactions of hydrated electrons, hydrogen atoms and hydroxyl radicals $\left(\cdot \mathrm{OH} / \bullet^{-} \mathrm{O}^{-}\right)$in aqueous solution. J. Phys. Chem. Ref. Data 17, 513-886.

Canonica, S., Tratnyek, P.G., 2003. Quantitative structure-activity relationships for oxidation reactions of organic chemicals in water. Environ. Toxicol. Chem. 22, 1743-1754.

Deborde, M., von Gunten, U., 2008. Reactions of chlorine with inorganic and organic compounds during water treatmentkinetics and mechanisms: a critical review. Water Res. 42, 13-51.

Deborde, M., Rabouan, S., Duguet, J.P., Legube, B., 2005. Kinetics of aqueous ozone-induced oxidation of some endocrine disurptors. Environ. Sci. Technol 39, 6086-6092.

Dodd, M.C., Huang, C.H., 2004. Transformation of the antibacterial agent sulfamethoxazole in reactions with chlorine: kinetics, mechanisms, and pathways. Environ. Sci. Technol 38, 5607-5615.

Dodd, M.C., Shah, A.D., von Gunten, U., Huang, C.-H., 2005. Interactions of fluoroquinolone antibacterial agents with aqueous chlorine: reaction kinetics, mechanisms, and transformation pathways. Environ. Sci. Technol 39, 7065-7076.
Dodd, M.C., Buffle, M.O., von Gunten, U., 2006. Oxidation of antibacterial molecules by aqueous ozone: moiety-specific reaction kinetics and application to ozone-based wastewater treatment. Environ. Sci. Technol 40, 1969-1977.

Dowideit, P., von Sonntag, C., 1998. Reaction of ozone with ethene and its methyl- and chlorine-substituted derivatives in aqueous solution. Environ. Sci. Technol 32, 1112-1119.

Gallard, H., von Gunten, U., 2002. Chlorination of phenols: kinetics and formation of chloroform. Environ. Sci. Technol $36,884-890$.

Gerrity, D., Gamage, S., Holady, J.C., Mawhinney, D.B., Quinones, O., Trenholm, R.A., Snyder, S.A., 2011. Pilot-scale evaluation of ozone and biological activated carbon for trace organic contaminants mitigation and disinfection. Water Res. 45, 2155-2165.

Hansch, C., Leo, A., Taft, R.W., 1991. A survey of Hammett substituent constants and resonance and field parameters. Chem. Rev. 91, 165-195.

Hansch, C., Leo, A., Hoekman, D., 1995. Exploring QSAR. Hydrophobic, Electronic, and Steric Constants. American Chemical Society, Washington, DC.

Hoigné, J., Bader, H., 1983a. Rate constants of reactions of ozone with organic and inorganic compounds in water-I. Nondissociating organic compounds. Water Res. 17, 173-183.

Hoigné, J., Bader, H., 1983b. Rate constants of reactions of ozone with organic and inorganic compounds in water-II. Dissociating organic compounds. Water Res. 17, 185-194.

Hoigné, J., Bader, H., 1994. Kinetics of reactions of chlorine dioxide (OClO) in water-I. Rate constants for inorganic and organic compounds. Water Res. 28, 45-55.

Hollender, J., Zimmermann, S.G., Koepke, S., Krauss, M., McArdell, C.S., Ort, C., Singer, H., von Gunten, U., Siegrist, H., 2009. Elimination of organic micropollutants in a municipal wastewater treatment plant upgraded with a full-scale postozonation followed by sand filtration. Environ. Sci. Technol 43, 7862-7869.

Hu, L., Martin, H.M., Arce-Bulted, O., Sugihara, M.N., Keating, K.A., Strathmann, T.J., 2009. Oxidation of carbamazepine by Mn(VII) and $\mathrm{Fe}(\mathrm{VI})$ : reaction kinetics and mechanism. Environ. Sci. Technol 43, 509-515.

Huber, M.M., Korhonen, S., Ternes, T.A., von Gunten, U., 2005. Oxidation of pharmaceuticals during water treatment with chlorine dioxide. Water Res. 39, 3607-3617.

Jonsson, M., Lind, J., Eriksen, T.E., Merenyi, G., 1993. O-H bond strengths and one-electron reduction potentials of multisubstituted phenols and phenoxy radicals-predictions using free-energy relationships. J. Chem. Soc., Perkin Trans. 2, 1567-1568.

Lee, Y., von Gunten, U., 2009. Transformation of $17 \alpha$ ethinylestradiol during water chlorination: effects of bromide on kinetics, products, and transformation pathways. Environ. Sci. Technol 43, 480-487.

Lee, Y., von Gunten, U., 2010. Oxidative transformation of micropollutants during municipal wastewater treatment: comparison of kinetic aspects of selective (chlorine, chlorine dioxide, ferrate ${ }^{\mathrm{VI}}$, and ozone) and non-selective oxidants (hydroxyl radical). Water Res. 44, 555-566.

Lee, Y., Yoon, J., von Gunten, U., 2005. Kinetics of the oxidation of phenols and phenolic endocrine disruptors during water treatment with ferrate (Fe(VI)). Environ. Sci. Technol 39, 8978-8984.

Lee, C., Yoon, J., von Gunten, U., 2007. Oxidative degradation of Nnitrosodimethylamine by conventional ozonation and the advanced oxidation process ozone/hydrogen peroxide. Water Res. 41, 581-590.

Lee, C., Lee, Y., Schmidt, C., Yoon, J., von Gunten, U., 2008. Oxidation of suspected N-nitrosodimethylamine (NDMA) precursors by ferrate(VI): kinetics and effect on the NDMA 
formation potential of natural waters. Water Res. 42, 433-441.

Lee, Y., Zimmermann, S.G., Kieu, A.T., von Gunten, U., 2009. Ferrate $(\mathrm{Fe}(\mathrm{VI}))$ application for municipal wastewater treatment: a novel process for simultaneous micropollutant oxidation and phosphate removal. Environ. Sci. Technol 43, 3831-3838.

Minakata, D., Li, K., Westerhoff, P., Crittenden, J., 2009. Development of a group contribution method to predict aqueous phase hydroxyl radical (HO*) reaction rate constants. Environ. Sci. Technol 43, 6220-6227.

Neta, P., Huie, E., Ross, A.B., 1988. Rate constants for reactions of inorganic radicals in aqueous solution. J. Phys. Chem. Ref. Data 17, 1027-1264.

Noorhasan, N., Patel, B., Sharma, V.K., 2010. Ferrate(VI) oxidation of glycine and glycylglycine: kinetics and products. Water Res. 44, 927-935.

Onstad, G.D., Strauch, S., Meriluoto, J., Codd, G.A., von Gunten, U., 2007. Selective oxidation of key functional groups in cyanotoxins during drinking water ozonation. Environ. Sci. Technol 41, 4397-4404.

Perrin, D.D., Dempsey, B., Serjeant, E.P., 1981. $\mathrm{pK}_{\mathrm{a}}$ Prediction for Organic Acids and Bases. Champman and Hall, New York.

Pierpoint, A.C., Hapeman, C.J., Torrents, A., 2001. Linear free energy study of ring-substituted aniline ozonation for developing treatment of aniline-based pesticide wastes. J. Agri. Food Chem. 49, 3827-3832.

Pinkston, K.E., Sedlak, D.L., 2004. Transformation of aromatic ether- and amine-containing pharmaceuticals during chlorine disinfection. Environ. Sci. Technol 38, 4019-4025.

Rebenne, L.M., Gonzalez, A.C., Olson, T.M., 1996. Aqueous chlorination kinetics and mechanism of substituted dihydroxybenzenes. Environ. Sci. Technol 30, 2235-2242.

Reungoat, J., Macova, M., Escher, B.I., Carswell, S., Mueller, J.F., Keller, J., 2010. Removal of micropollutants and reduction of biological activity in a full scale reclamation plant using ozonation and activated carbon filtration. Water Res. 44, 625-637.

Rosario-Ortiz, F.L., Wert, E.C., Snyder, S.A., 2010. Evaluation of $\mathrm{UV} / \mathrm{H}_{2} \mathrm{O}_{2}$ treatment for the oxidation of pharmaceuticals in wastewater. Water Res. 44, 1440-1448.

Schwarzenbach, R.P., Gschwend, P.M., Imboden, D.M., 2003. Environmental Organic Chemistry, second ed. John Wiley \& Sons, Inc., New Jersey.
Schwarzenbach, R.P., Escher, B.I., Fenner, K., Hofstetter, T.B., Johnson, C.A., von Gunten, U., Wehrli, B., 2006. The challenge of micropollutants in aquatic systems. Science 313, 1072-1077.

Schwarzenbach, R.P., Thomas, E., Hofstetter, T.B., von Gunten, U., Wehrli, B., 2010. Global water pollution and human health. Annual Review of Environment and Resources 35, 109-136.

Sharma, V.K., Burnett, C.R., Millero, F.J., 2001. Dissociation constants of the monoprotic ferrate(VI) ion in $\mathrm{NaCl}$ media. Phys. Chem. Chem. Phys. 3, 2059-2062.

Sharma, V.K., Mishra, S.K., Nesnas, N., 2006. Oxidation of sulfonamide antimicrobials by ferrate(VI) $\left[\mathrm{Fe}^{\mathrm{VI}} \mathrm{O}_{4}^{2-}\right]$. Environ. Sci. Technol 40, 7222-7227.

Snyder, S.A., Wert, E.C., Rexing, D.J., Zegers, R.E., Drury, D.D., 2006. Ozone oxidation of endocrine disruptors and pharmaceuticals in surface water and wastewater. Ozone Sci. Eng 28, 445-460.

Suarez, S., Dodd, M.C., Omil, F., von Gunten, U., 2007. Kinetics of triclosan oxidation by aqueous ozone and consequent loss of antibacterial activity: relevance to municipal wastewater ozonation. Water Res. 41, 2481-2490.

Ternes, T.A., Joss, A., 2006. Human Pharmaceuticals, Hormones and Fragrances. The Challenge of Micropollutants in Urban Water Management. IWA Publishing, London, New York.

Theruvathu, J.A., Flyunt, R., Aravindakumar, C.T., von Sonntag, C., 2001. Rate constants of ozone reactions with DNA, its constituents and related compounds. J. Chem. Soc., Perkin Trans. 2, 269-274.

Tratnyek, P.G., Hoigne, J., 1994. Kinetics of reactions of chlorine dioxide $(\mathrm{OClO})$ in water-II. Quantitative structure-activity relationships for phenolic compounds. Water Res. 28, 57-66.

von Gunten, U., 2003. Ozonation of drinking water: Part I. Oxidation kinetics and product formation. Water Res. 37, 1443-1467.

Zimmermann, S.G., Schmukat, A., Schulz, M., Benner, J., von Gunten, U., Ternes, T.A., 2012. Kinetic and mechanistic investigations of the oxidation of tramadol by ferrate and ozone. Environ. Sci. Technol 46, 876-884.

Zimmermann, S.G., Wittenwiler, M., Hollender, J., Krauss, M., Ort, C., Siegrist, H., von Gunten, U., 2011. Kinetic assessment and modeling of an ozonation step for fullscale municipal wastewater treatment: micropollutant oxidation, by-product formation and disinfection. Water Res. 45, 605-617. 